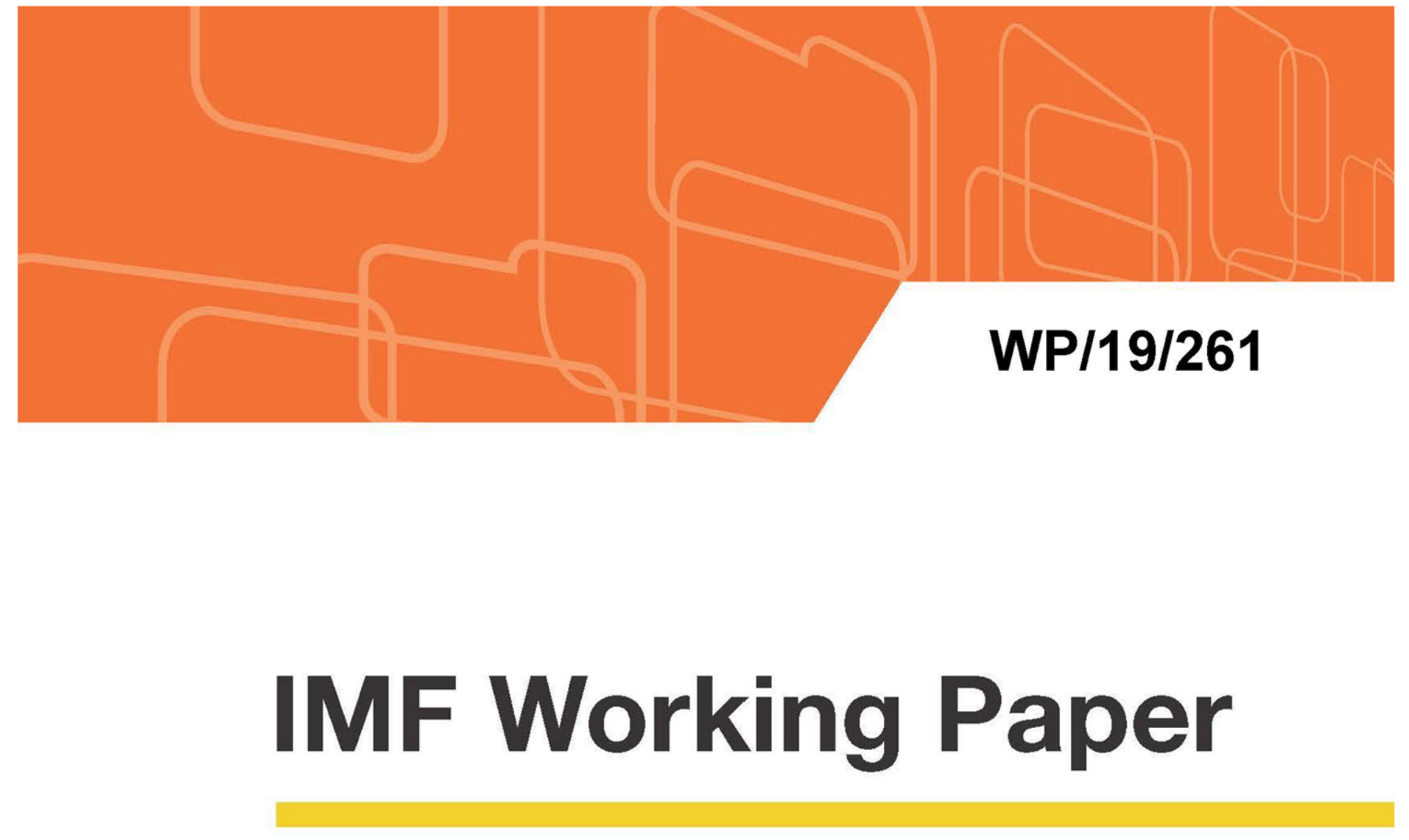

\title{
Guilt, Gender, and Work-Life Balance in Japan: A Choice Experiment
}

by Chie Aoyagi and Alistair Munro

IMF Working Papers describe research in progress by the author(s) and are published to elicit comments and to encourage debate. The views expressed in IMF Working Papers are those of the author(s) and do not necessarily represent the views of the IMF, its Executive Board, or IMF management. 


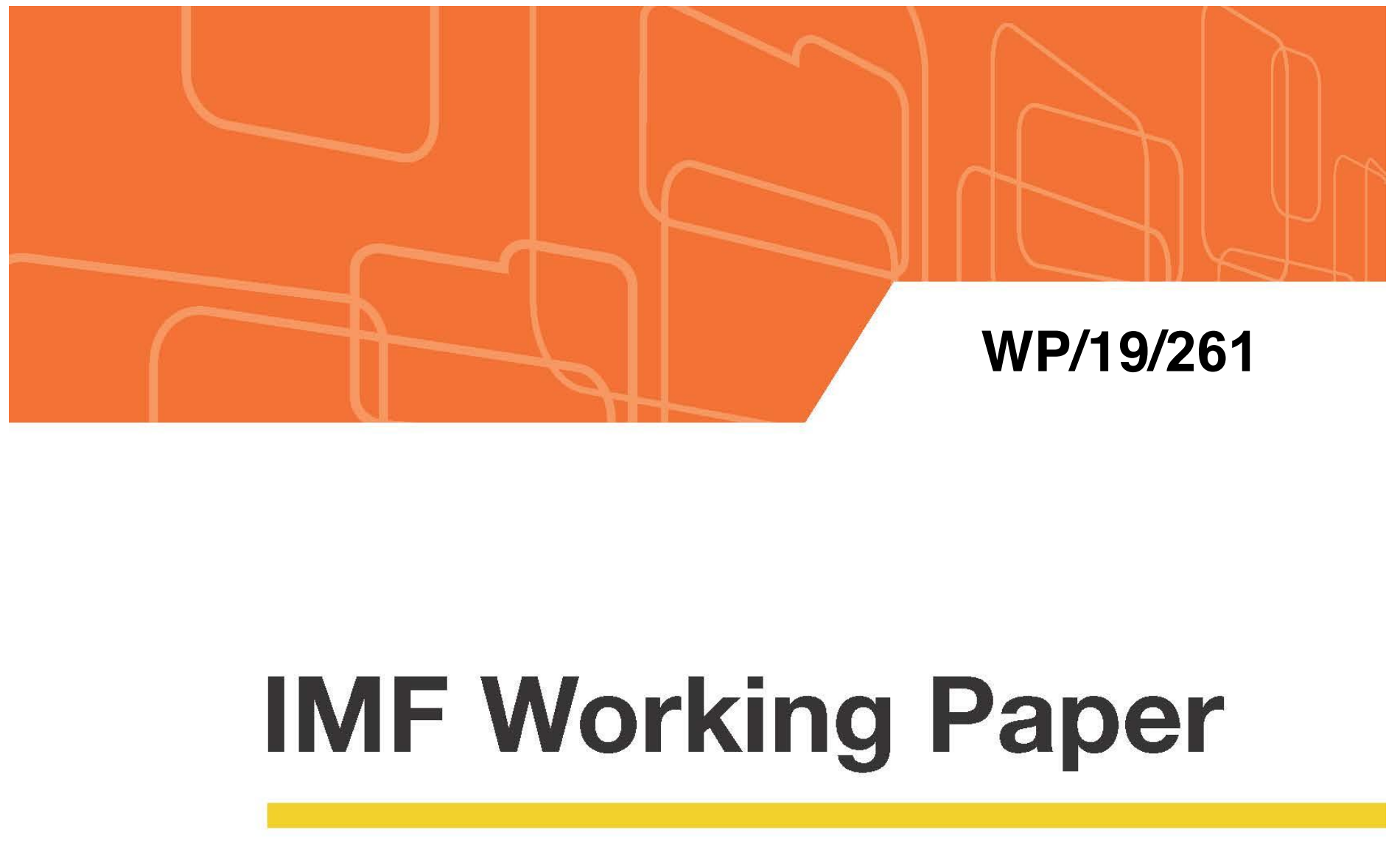

\section{Guilt, Gender, and Work-Life Balance in Japan: A Choice Experiment}

by Chie Aoyagi and Alistair Munro

IMF Working Papers describe research in progress by the author(s) and are published to elicit comments and to encourage debate. The views expressed in IMF Working Papers are those of the author(s) and do not necessarily represent the views of the IMF, its Executive Board, or IMF management.

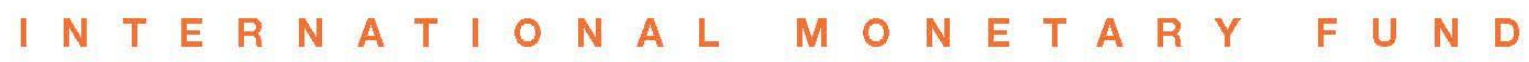




\title{
IMF Working Paper
}

Statistics Department

\section{Guilt, Gender, and Work-Life Balance in Japan: A Choice Experiment ${ }^{1}$ Prepared by Chie Aoyagi and Alistair Munro}

Authorized for distribution by Patrizia Tumbarello

November 2019

\section{IMF Working Papers describe research in progress by the author(s) and are published to elicit comments and to encourage debate. The views expressed in IMF Working Papers are those of the author(s) and do not necessarily represent the views of the IMF, its Executive Board, or IMF management.}

\begin{abstract}
The quantification of how aspects of a job are valued by employees sheds light on the potential for labor market reform in Japan. Using a nationwide sample of 1,046 working-age adults, we conduct a choice experiment that examines individuals' willingness to trade wages against job characteristics such as the extent of overtime, job security, the possibility of work transfer and relocation. Our results suggest that: i) workers have high WTP (willingness to pay) to avoid extreme overtime and work transfer, ii) women have higher WTP than men, and iii) higher WTP for women are driven in part by feelings of guilt.

JEL Classification Numbers: J28, D91, C9

Keywords: Work-life balance, discrete choice experiment, labor market reform, guilt, Japan Authors’ E-Mail Address: caoyagi@imf.org, alistair-munro@grips.ac.jp

\footnotetext{
${ }^{1}$ We would like to thank Koji Yokota (Meisei University) and Monique Newiak (IMF) for being the discussant at the 15th International Conference WEAI 2019 and at the Statistical Innovation Talks series at the International Monetary Fund respectively. We are also very grateful for comments from Gabriel Quirós Romero, Tamim Bayoumi, the Japan team in Asia Pacific Department led by Paul Cashin, Jose Daniel Rodríguez-Delgado, and William Gbohoui (all IMF). This paper is based on Chapter 2 of Chie Aoyagi's Ph.D. dissertation at the National Graduate Institute for Policy Studies (GRIPS) in Tokyo under the supervision of Alistair Munro. Kathie Jamasali provided administrative assistance.
} 
ABSTRACT

I. INTRODUCTION

II. BACKGROUND

III. DESIGN AND METHOD

IV. ESTIMATION MODELS

V. BASIC INFORMATION ABOUT THE CHOICE EXPERIMENT

VI. RESULTS OF THE CHOICE EXPERIMENT

A. Main Effects and the WTPs

B. WTPs Based on Different Socio-Demographic Characteristics

$\underline{20}$

VII. GUILT EFFECTS $\underline{23}$

VIII. POLICY IMPLICATIONS AND CONCLUSIONS $\underline{26}$

REFERENCES $\underline{28}$

\section{TABLES}

1. Attributes and Levels

2. Choice Set Example

3. Mean Comparisons of Selected Socio-Demographic Variables

4. A Benchmark Econometric Model (Model 1)

5. WTPs by Different Amount of Annual Wage (Including Overtime Pay)

6. WTP Estimation for Wage 3 Million Yen in their 30s

7. Testing Differences in WTP for 4-Year College or Higher Respondents

8. Mean Guilt

9. Guilt, WTP, and Gender

10. Women, Guilt, and WTP for Reducing Overtime

$\frac{25}{25}$

\section{APPENDICES}

1. Key Parts of the Survey Questionnaire

2. Extended Model (Model 2) 


\section{INTRODUCTION}

1. For most individuals, a good balance between life and work depends on the interaction of multiple factors related to the job and work environment (Baum and Kabst 2013). The traditional way of understanding preferences in this context is by means of the hedonic wage model in which market data on wages are related to job characteristics (Rosen (1974); Sakai (2014)). This method has the strong advantage of being based on revealed choices, but it also has a number of drawbacks particularly when new policies for market reform are being considered. There are for example, well-known problems of identifying preferences from market data (Ekeland, Heckman and Nesheim 2004). These are particularly acute when non-marginal changes in job characteristics are being estimated or we are interested in the views of people who are currently outside the labor market. In addition, job characteristics such as working hours are often standardized in reality and for a variety of reasons, including the desirability of coordinating work, the variation in the characteristics found in samples can be small compared to the feasible range of characteristics.

2. In this paper we take an innovative approach, using a choice experiment methodology and a specially commissioned survey. Unlike revealed choice data, choice experiment consists of choices made in hypothetical situations. Since the experimenter chooses the options this deals directly with some identification issues and it also enables a wide range of job characteristics and policy reforms to be considered. Choice experiments can also be used for people who are not currently employed. While choice experiment methods are widely employed in environmental and health economics (Swait and Adamowicz (2001); de BekkerGrob, Ryan and Gerard (2012)) their use in labor economics has been largely limited to understanding the preferences of healthcare workers (e.g. (Sivey, et al. 2012)- though see Mas and Pallais (2017) for recent use in call center jobs). This paper contributes to the choice experiment literature by estimating the willingness to pay (WTP) of workers to enjoy better work-live balance (avoid extreme overtime, compulsory relocation and transfers, and job insecurity).

3. Choice experiments have their own perceived weaknesses, of course, most prominently being the fact that the decisions are hypothetical. Nevertheless, the theory of planned behavior developed by Ajzen (1991) provides support for the validity of choice experiments as do experiments for consumer products where hypothetical and actual choices are compared (Chang, Lusk and Norwood. 2009). Perhaps more importantly, our focus here is on work-life balance in Japan, a country where there is no publicly available, large-scale reliable data on pay and job characteristics (Yamada and Kawaguchi 2015). This creates a comparative advantage for the choice experiment method.

4. Our context is provided by the continuing debate over work-life balance, which has become particularly acute in Japan, a country well-known for its long-hours culture.

Typically, regular workers in Japan enjoy very stable employment (Kanemoto and MacLeod (1991); Yamada and Kawaguchi (2015)) but they are often required to work overtime and to 
follow their employers' orders to relocate or transfer to different work within the same location regardless of their own preferences (Sato, Fujimura and Yashiro (2007); Tsuru (2014)). Possibly this work style made more sense during economic growth period between the 1960s and 1980s, when most women quit their jobs after getting married so as to fulfil their responsibilities to care for their families and homes, while their husbands specialized in paid jobs and became the sole breadwinners in the household. However, prolonged economic stagnation and subdued wage growth after the burst of the bubble in the 1990s made it more difficult for families to continue with that life style (Imano (2012); H. Yamada (2017)), as reflected in the fact that the number of dual earner households has exceeded the number of single earner households (with working husband and stay-home wife) since 1997 (Cabinet Office 2014).

5. Nowadays, the nature of the typical Japanese work style makes it difficult for both the man and the woman in a family with children to stay in a regular employment and usually the woman ends up taking non-regular work, in line with traditional gender roles (Steinberg and Nakane (2012); Miake (2017)). Indeed, much of the increase in women's labor participation in recent years represents non-regular jobs with lower wages, training and career opportunities (Colacelli and Le 2018). Although families have seemingly developed strategies to cope with prolonged economic stagnation by adopting different employment pattern between men and women, according to the OECD Better Life Index, Japan ranks $35^{\text {th }} / 40$ in the international comparison of work-life balance indicators. ${ }^{2}$ As such, policy makers have concluded that Japanese labor market practices must be reformed in order to meet growing workers' demand for flexible work arrangement (Cabinet Office 2017).

6. If regular jobs which put a "limit" on obligations such as long overtime and mandatory relocation and transfer were widely available, it would help to balance work and family responsibilities for both male and female workers. Therefore, it has been widely suggested that the main component of any work style reform plan should be the dissemination of the use of limited-regular (in Japanese gentei seishain) contracts (Imano (2012); Tsuru (2014)). Not only it would improve individual satisfaction, such labor market reform could have higher output and inflation impact than any other structural reforms could have in the economy with aging and shrinking population (IMF 2018). Colacelli and Fernandez C. (2018) estimate that a gradual introduction of limited-regular contracts (replacing regular and non-regulars over time) would boost the level of labor productivity in Japan by over 7 percent in the long-run. The key question is therefore what form should these limited regular contracts take? Answering that question requires some understanding of worker preferences. This is the motivation for our study.

7. In addition to applying the choice experiment method to the study of work-life balance and using the estimates to cast light on the issue of labor market reform in Japan, our

${ }^{2}$ Data accessed on July 11, 2019 on the OECD website (http://www.oecdbetterlifeindex.org/topics/work-lifebalance/). 
contribution is to bring in a behavioral angle to the debate. It is often reported that guilt about work-life dilemmas tends to differ according to gender (Martínez, et al. 2011), especially when issues of child-care are involved (Shimazu, et al. 2013). As part of the experiment we investigate the extent to which guilt drives differences in the mean willingness of men and women to accept trade-offs in job features that affect work-life balance.

8. The paper is organized as follows: in the following sections after this introduction, we briefly provide a background on the use of choice experiments in labor economics and prior evidence on the value of work. We then set out the design of our experiment before reporting the results in sections 6 and 7 and providing some concluding thoughts in section 8 .

\section{BACKGROUND}

9. Only a small number of studies have applied a choice experiment to job market research, and the majority of them examine job preferences of health/medical professionals particularly with regard to location options in developing countries (Lagarde and Blaauw 2009). Outside this literature, the number of studies is very limited and largely uses university students or labor market entrants as subjects. Baum and Kabst (2013), for example, capture the preferences of graduate job seekers by conducting a choice experiment using graduate and undergraduate students in a German university, using the ten highest ranked job choice factors as attributes in experiments (with all non-wage attributes having two levels.) ${ }^{3}$ Two other more recent studies worth mentioning include Mas and Pallais (2017) and Wiswall and Zafar (2018). The former applied the choice experiment to call center job applicants in the U.S. and the latter to undergraduate students at New York University. Both studies found women's willingness to pay (WTP) for flexible work arrangement is higher than men's. ${ }^{4}$ Mas and Pallais (2017) is notable in that they provide some evidence for the external validity of choice experiment methods: subjects who eventually applied for the job were more likely to have preferences that fitted the job specification, compared to those who did not pursue the initial enquiry further. One study that studies a more general subject pool is Yoo and Oh (2017) who identified policy measures to improve female labor participation and to narrow the gender wage gap by applying the choice experiment methodology in South Korea. They used five attributes including factors important for work-life balance and find a high WTP for work-place childcare. $^{5}$

\footnotetext{
${ }^{3}$ The 10 factors are work climate, security, work-life balance (operationalized by flexible working hours and working schedule), training, salary, person-organization fit, promotion prospects, task attractiveness and location.

${ }^{4}$ The main flexible-work attributes of interest in those paper include flexible work scheduling, working from home, and the employer discretion over scheduling (Mas and Pallais 2017) and dismissal probability and work hours flexibility (Wiswall and Zafar 2018).

${ }^{5}$ The five factors are annual salary, weekly working hours, and firm size, availability of parental leave, and a workplace childcare center.
} 
10. Although the relevant choice experiment literature is sparse, as we stated above, there are other ways of calculating labor market trade-offs, including the hedonic pricing model. This approach faces two challenges: first, identification, which is particularly acute when selection into the market is a part of the equilibrium or when the functional form for the relationship is unknown and possibly non-linear (Heckman, Matzkin and Nesheim 2010). Even when the value of marginal changes in job characteristics are identified, it may not be possible to identify the value of the kind of non-marginal changes often involved in labor market reform. Secondly, there must be adequate data. In fact, there is no suitable official, large-scale and reliable data on pay and job characteristics for Japan.

11. Nevertheless, there are some studies that use especially commissioned surveys or use indirect methods to estimate WTP. Toda (2015) for example, used the 2012 Working Person Survey conducted by a private research firm, Recruit Works Institute, covering nearly 1,000 people aged 18-59 who live in Tokyo and surrounding prefectures. After controlling for variables in standard wage regressions, including years of tenure and educational levels of the worker, the author found that there is a 10 percent hourly wage discount to have a limit on work location for employees in big companies, and a 10 percent hourly wage discount for having limit on work hours for female workers. Other study (Kuroda and Yamamoto 2013) also found negative wage implications for having access to company's work-life-balance policies especially for male workers.

12. In contrast to the above two studies, Yasui et al, (2016) concluded there are no such wage penalty for limited-regular workers. Using the Blinder-Oaxaca decomposition to analyze an online survey, covering about 2000 people aged 15 and above who work in big firms (RIETI 2015), they found that although workers limited by their work location and work contents receive statistically lower "monthly" wages than unlimited workers, about 80 percent and 90 percent of the wage differences respectively can be explained by the difference in observed characteristics which are included in standard wage regressions. ${ }^{6}$ Moreover, when it comes to "hourly wages", surprisingly, their results show all types of limited-regular workers receive statistically higher (not lower) wages than unlimited regular workers after controlling for the observed characteristics. These different findings across studies suggest that the extent of the possible wage cut for a worker to adopt more worker friendly working style could vary depending on work location, company size, and whether it is white-collar job or not.

13. While the hedonic pricing analyses are based on the current distribution of various types of workers and their jobs, how much it can be applied to the potential cases under the reform scenario is questionable because the variation in contracts within the surveys is quite small. Some studies with changes in hypothetical wage and job characteristics have been conducted for Japan, usually in designs in which subjects are asked for their minimum

\footnotetext{
${ }^{6}$ The controlled characteristics are gender, education, age, age squared, yeas of tenure, years of tenure squared, industry, occupation, marital status, number of children, prefecture of residence, and hours of work.
} 
acceptable wage increase to accept a single, specific reduction in work quality. For example, Morikawa (2010) used an individual survey conducted by Ministry of Economy Trade and Industry (2006), which asked people aged 20-60 how much wage premium they request (ranging from +0 percent to +50 percent of a typical regular worker's wage) in order to accept an unstable employment and some possibility of mandatory relocations or intra-firm transfers. The result suggests on average, people asked for 10 percent of wage premium for both accepting an unstable employment and some possibility of mandatory relocations and intra-firm transfers.

14. Kume et al, (2014) confirm the earlier findings using an online survey. After excluding some invalid responses, the respondents on average asked for 21 percent premium for having unstable job and 19 percent for having been exposed to the risk of mandatory relocations/intra-firm transfers. ${ }^{7}$ Similarly, Tsuru et al, (2013) found their respondents on average asked for a 20 percent premium for switching to an unstable job and 27 percent for switching to a job with a risk of mandatory relocations/intra-firm transfers. Meanwhile, Kuroda and Yamamoto (2013) pose hypothetical questions to both employers and employees, to see how much wage cut is justifiable to introduce work-life balance policies in a company (RIETI 2012). They find there are potential Pareto improvements: after excluding invalid responses, on average, workers seem to accept a lower wage (about 20 percent lower than the current wage) than companies would offer (about 10 percent lower), when they see the wider value of having the work-life balance policies available at their company. ${ }^{8}$

15. Collectively, these studies take us away from revealed preference data and provide evidence on trade-offs for significant changes to the working environment, but they focus on one or two job features at a time and have a limited investigation of heterogeneity amongst responses. It is these features that we seek to remedy in our design.

\section{DESIGN AND METHOD}

16. The main design dimensions of a choice experiment are number of choice sets, alternatives, and attributes, and number and range of attribute levels. A choice set refers to a group of alternative options which the respondent is asked to rank or to choose one from. Alternatives are the members of the choice set. Attributes are the features of the alternative, such as wage, overtime requirements and so on, while levels are the particular values for attributes, such as a wage of 3 million yen. Jobs differ in many dimensions and it is therefore tempting to design an experiment where the choice set is highly complex. However, while more complex experimental design would yield richer data, respondent ability to process complex information is limited, and complex experimental design could result in incomplete responses or inconsistent choices as emphasized in Hensher (2010). Inconsistent results can

\footnotetext{
${ }^{7}$ About 30 percent of respondents chose "I don't know" and did not select any of the listed wage levels.

${ }^{8}$ 40-60 percent of workers/companies responded they want 0 percent/100 percent wage cut for having WLB policies, indicating they would not want WLB policies to be implemented at any wage rate.
} 
occur if subjects simplify complex information by considering only a portion of the information available in the choice set, or if they make more mistakes (Chung, Boyer and Han 2011). There have been efforts to test those effects empirically, for example the former effect (respondents' developing own simplified decision rules) can be captured as biased estimates of attribute weights, or WTP; and the latter effect (increased respondent error) can be captured as larger error variance (Johnson, et al. 2013).

17. While the problem of design complexity is widely understood, so far there is no agreement in the literature as to optimal choice experiment task complexity, in part because those studies vary in field of study and experimental design. For example, when determining the number of choice sets, we need to strike the right balance in terms of number of items that the respondents can learn from repeated choice tasks without excessive fatigue. While larger number of choice sets might increase the number of dropouts (Meyerhoff, Oehlmann and Weller 2015) and increase status quo bias (Oehlmann, et al. 2017), too small a number of choice sets may also give rise to problems. Chung, Boyer and Han (2011) found that on average variance of error first decreases, then increases with increasing number of choice sets presented to the respondent, with the optimal number of choice sets per survey being six. Similarly, Caussade, et al. (2005) observe a U-shaped relationship with error variance decreasing in up to nine or ten choice situations.

18. Meanwhile, if the number of attributes is too small, participants may not find enough information to make choices to reflect their preferences, but if the number is too large, the cognitive load associated with greater information outweighs the potential increase in consistency induced by a more complete description of the alternative. DeShazo and Fermo (2002) and Caussade, et al. (2005) provide evidence suggesting that an increase in the number of attributes results in an increase in error variance. Meanwhile, Meyerhoff, Oehlmann and Weller (2015) find that the probability of abandoning the survey significantly increases with the number of attributes. Furthermore, as the number of levels increases, the number of comparisons increases and in turn experimental complexity increases (Caussade, et al. 2005).

19. Given these trade-offs, we conducted a literature review and three focus group interviews to determine the final attributes and their levels, as well as the vocabulary and language to be used in the survey. The literature review for this part of the study consists of two main components: job choice decisions in general, and discussions on Japanese work style reform. Three focus groups were conducted during summer of 2017. Participants were selected on the criteria listed in (Rabiee 2004) that they would have something to say on the topic, are within the age-range of the targeted survey respondents, have similar sociocharacteristics and would be comfortable talking to the interviewer and each other: All selected participants were currently working, in their $20 \mathrm{~s}-40$ s, and belonging to the preformed groups. In all three focus groups, one of us acted as the interviewer, and in two of the three focus group interviews, there was another person acting as a note-taker. The majority of participants mentioned an appropriate level of wage as a factor which they look 
for in a job. The tolerance to wage cut varied among participants. Work culture or policies related to work day and time also received a lot of interest. Many agreed that excess overtime should be avoided. While some prefer zero overtime, others say up to certain level (like regularly working until $8 \mathrm{PM}$ ) is "not a big problem" but overtime above that level should be avoided. There was no discussion about part-time or shortened work hours, probably because all participants are currently working full-time. Some people raised the issue of work location.

20. Based on the interviews we selected five attributes for our design: wage level, required overtime, job security, mandatory relocation and mandatory transfer. We discuss the levels of the attributes in more detail below but here we just clarify the last two attributes. It is common in Japan for white-collar workers to have contracts which allow the company to mandatorily relocate the worker to another branch in the country, either for a short or extended period. Obviously, this is potentially highly disruptive to family life. Mandatory transfer, on the other hand, refers to moving the worker to a different department at the same or nearby location. This is potentially less disruptive to family life but can be an important feature of the job that provokes strong reactions from some workers.

21. The levels for the attributes were selected in order to cover a reasonable range of job features for typical regular jobs in Japan. ${ }^{9}$ Table 1 below shows the level and ranges of the attributes. In particular, the cut off overtime hour of 15 hours per month is the median reported by the Ministry of Health Labor and Welfare in the 2018 Karoshi white paper for full-time regular workers in Japan. The 45 hours per month cut-off is the legal limit for overtime at normal time, though during busy seasons of a year, companies are allowed to go over the limit under certain conditions. The employment security of "high" reflects the stability enjoyed by current regular workers, and as regular workers are traditionally said to have lifetime employment in Japan, this level provides the maximum job security. While the alternative, "medium" employment security is somewhat lower than the regular workers' job security, it is still higher than the non-regular worker's job security level ("low") which is not included in the choice set. As exact measure of employment security is difficult to obtain in reality, lengths of average tenure for regular workers, limited-regular workers, and nonregular workers are used as a proxy of high, medium and low security and are provided to respondents as an illustration. This information as well as some other explanation of each attributes and their levels are given to respondents as reference information before they start considering the choice sets. The "baseline" tag in the table means that these are the omitted variables in the regression equations - it is not information that was presented to participants.

\footnotetext{
${ }^{9}$ The purpose of the wage thresholds is to estimate the coefficient on wages and wage squared, so the consideration was given to set the level of wages which is realistic for a given set of job characteristics. About half of current wage earners in our sample earn between 3 million yen and 8 million yen a year.
} 
Table 1. Attributes and Levels

\begin{tabular}{ll}
\hline \multicolumn{1}{c}{ Attribute } & Level \\
\hline Wage 1 (Baseline) & 3 million yen \\
Wage 2 & 3.5 million yen \\
Wage 3 & 4 million yen \\
Wage 4 & 6 million yen \\
Wage 5 & 7 million yen \\
Wage 6 & 8 million yen \\
Overtime 1 (Baseline) & 0 hours per month \\
Overtime 2 & $0-15$ hours per month \\
Overtime 3 & $15-45$ hours per month \\
Overtime 4 & 45 - hours per month \\
Relocation 1 (Baseline) & Zero possibility of relocation \\
Relocation 2 & Some possibility of relocation \\
Transfer 1 (Baseline) & Zero possibility of transfer \\
Transfer 2 & Some possibility of transfer \\
Security 1 (Baseline) & As secure as regular contracts \\
Security 2 & Less secure than regular contracts \\
\hline
\end{tabular}

22. With five attributes and several levels for each attribute, in theory there are 192 possible combinations. Obviously, it is difficult to get subjects willing to face such a lengthy list of choices - as we point out above, a typical experiment involves less than 10 choice sets, often with only two or three options. Given the potentially large number of unique choices, some sort of fractional (i.e. less than 192 questions) design is typically used in choice experiments. The traditional orthogonal fractional factorial designs minimize the correlations evidenced within a design to zero. In contrast, statistically efficient designs of various kinds optimize the amount of information obtained from a design (Hensher, Rose and Greene 2005). Efficient designs are based on minimizing the size of the variance-covariance matrix given a prior for the parameters to be estimated. There are various ways of calculating the size of a matrix, which lead to different efficiency measures (Train (2003); Hole (2015)). The most commonly used efficiency measure is D-efficiency which minimizes the determinant of the covariance matrix and this is the procedure we use here. Now, efficient designs rely on the researcher having some reasonable prior beliefs about the sign and strength of different coefficients. An important point is that orthogonal designs are only efficient when the coefficients on the attributes are zero. In our case, for example, we expect the effect on utility of wages to be positive and increasing and we anticipate the effect of extreme overtime to be negative and worse than less extreme overtime. On the other hand, we have no clear prior about the benefit or disutility of within-company transfers to other departments, in which case we might start with the conjecture that the coefficient on this variable is zero. We use these rough conjectures to design a pilot (see below) with 100 subjects using the DCREATE command in STATA (Hole 2015). The results of the pilot are then used to update the design for the main survey. 
23. As for the number of choice sets faced by each participant and the number of alternatives in each choice set, here we stick to the conventions and offer each subject eight choice sets consisting of three alternative jobs. Respondents were randomly assigned into four blocks, with each block of respondents facing different set of choice sets. In other words, the choice experiment has 32 different choice sets in total, but each individual only needs to consider eight choice sets to limit their cognitive burden and avoid exhaustion effects. Table 2 below shows an example choice set. Job A, Job B, Job C are the three alternatives. Each alternative is described by five attributes, annual wage, overtime, employment security, transfer possibility and relocation possibility. Each respondent sees eight choice sets repeatedly, for each choice-set making two decisions, the best job and the worst job to choose from the three alternatives.

\begin{tabular}{cccc}
\hline \multicolumn{4}{c}{ Table 2. Choice Set Example } \\
\hline & Job A & Job B & Job C \\
\hline Annual Wage & 6 million yen & 7 million yen & 8 million yen \\
Overtime & 0 hours/month & 15-45 hours/month & 0 hours/month \\
Employment & Medium & High & Medium \\
Transfer Possibility & Some & None & None \\
Relocation & None & None & Some \\
\hline \multicolumn{5}{c}{} & & & \\
\hline Best Job & $\bigcirc$ & Job B & Job C \\
\hline Worst Job & $\bigcirc$ & $\bigcirc$ & $\bigcirc$ \\
\hline
\end{tabular}

24. A pilot experiment with 107 subjects was conducted in November 2017, one month before the actual choice experiment. Besides the timing of the surveys, the pilot experiment and the real experiment differ only on the number of respondents (effective respondence in the pilot experiments were about 1/10 of the size), and the existence of one question, which was deemed necessary and added after the pilot experiment. The added question asks what attributes respondents ignored when making stated choice decisions (Q29 in Appendix 1). The coefficients obtained from the preliminary regression analysis using the pilot data were adopted as the prior for getting D-efficient design of the stated choice survey. However, the resulting efficiency level was not very different from the initial design. Moreover, the resulting choice sets were also similar, so in order not to disturb a design that appeared to work well the initial design was carried in the actual choice experiment.

\section{Estimation Models}

25. The random utility model (Train 2003) provides the underlying framework for understanding data from a choice experiment. The basic specification of the model is

$$
\mathrm{U}_{i j}=\mathrm{V}\left(\mathrm{s}_{i}, \mathrm{X}_{i j}\right)+\varepsilon_{i j}=\mathrm{V}_{i j}+\varepsilon_{i j}
$$


where $V_{i j}$ is the utility for the representative individual and is a deterministic component of the model, while the stochastic component $\varepsilon_{i j}$ is assumed to follow some distribution function. The subscripts $\mathrm{i}$ refer to person $\mathrm{i}$ while $\mathrm{j}$ is the alternative in the choice experiment; $s_{i}$ represents characteristics of the person, and a vector of attributes for each element in the choice set is labelled $x_{i j}$. Let $j=1, \ldots, J$, be the alternatives in a choice set and use $\mathrm{k}$ to indicate the chosen alternative. The key assumption of the random utility model is that the alternative chosen has the highest utility. In a ranking exercise, the assumption means that the ranks correspond to the order of the utilities.

26. For notational simplicity, we drop the person index. For computational simplification, choice experiment analyses often rely on logit model (Beggs, Cardell and Hausman 1981). Specifically, the $\varepsilon_{j}$ s are assumed to be independently and identically distributed extreme value random variates. The usual logit derivation that the probability that $\mathrm{U}_{j}>\mathrm{U}_{k}$ can be computed as

$$
\operatorname{Pr}\left(\mathrm{U}_{j}>\mathrm{U}_{k}, \mathrm{j} \neq \mathrm{k}\right)=\mathrm{e}^{\mathrm{Vj}} /\left(\mathrm{e}^{\mathrm{Vj}}+\mathrm{e}^{\mathrm{Vk}}\right)
$$

The rank ordered case can then be computed as the extension of eq(2):

$$
\operatorname{Pr}\left(\mathrm{U}_{\boldsymbol{l}}>\mathrm{U}_{2} \ldots>\mathrm{U}_{\boldsymbol{H}}, \text { for } \mathrm{H} \leq \mathrm{J}\right)=\prod_{\mathrm{h}=1}^{\mathrm{H}}\left[\mathrm{e}^{\mathrm{Vh}} / \sum_{\mathrm{m}=\mathrm{h}}^{\mathrm{H}} \mathrm{e}^{\mathrm{Vm}}\right]
$$

27. Where $\mathrm{J}=$ number of alternatives and $\mathrm{H}=$ number of alternatives ranked. In particular, $\mathrm{J}=\mathrm{H}=3$ for the choice experiment in this paper. As specified, a particular linear in parameter form for $\mathrm{V}_{i j}$ in eq(1), is $\mathrm{V}_{i j}=\mathrm{Z}_{i j} \beta$ where the $\mathrm{Z}_{i j} \mathrm{~s}$ are combinations of the $\mathrm{s}_{i}$ and $\mathrm{x}_{i j} \mathrm{~s}$. Then for a particular person $i$ the ranking of his/her $J$ choices can be written as $R_{i}=\left(r_{1}, \ldots, r_{j}\right)$ so that the probability of the observed ranking is:

$$
\pi\left(\mathrm{R}_{i}\right)=\operatorname{Pr}\left(\mathrm{U}_{r l}>\mathrm{U}_{r 2} \ldots>\mathrm{U}_{r j}\right)=\prod_{\mathrm{h}=1}^{\mathrm{J}-1}\left[\exp \left(\mathrm{Z}_{i r h} \beta\right) / \sum_{\mathrm{m}=\mathrm{h}}^{\mathrm{J}} \exp \left(\mathrm{Z}_{i r m} \beta\right)\right]
$$

28. Since for $\mathrm{h}=\mathrm{J}$ the numerator and denominator cancel. For example, when $\mathrm{h}=\mathrm{j}=3$, this simplifies as

$$
\pi\left(\mathrm{R}_{\boldsymbol{i}}\right)=\left(\exp \left(z_{i 1} \beta\right) / \sum_{r m=1}^{3} \exp \left(z_{i r m} \beta\right)\right)\left(\exp \left(z_{i 2} \beta\right) / \sum_{r m=2}^{3} \exp \left(z_{i r m} \beta\right)\right)
$$

$=($ probability the best alternative is chosen from full choice set)(probability runner-up is chosen from choice set without the best alternative) 
For an independent sample of $\mathrm{N}$ individuals, the log likelihood is

$$
\begin{gathered}
\mathrm{L}(\beta)=\sum_{\mathrm{i}=1}^{\mathrm{N}} \log \pi\left(\mathrm{R}_{i}\right) \\
=\sum_{i=1}^{N} \sum_{h=1}^{J-1} Z_{i r h} \beta-\sum_{i=1}^{N} \sum_{h=1}^{J-1}\left\lfloor\log \sum_{m=h}^{J} \exp \left(Z_{i r m} \beta\right) \mid\right.
\end{gathered}
$$

29. The log likelihood function is globally concave in $\beta$ so that a unique maximum exists (Beggs, Cardell and Hausman 1981). Note that the individual $\beta$ s are not identified in the logit model. Rather the multiplication $\lambda \beta$ is identified (where $\lambda$ is the scale parameter defined as $\lambda=\sqrt{\frac{\pi^{2}}{6 \sigma^{2}}}$, where $\pi^{2}$ is a constant and $\sigma^{2}$ is the variance of $\varepsilon$ ) (Hensher, Rose and Greene 2005).

We fill in the deterministic part of an individual's utility in equation (1) using the attributes and levels as defined in Table 1:

$$
\begin{aligned}
\mathrm{V}=\beta_{0}+\beta_{1} \text { wage } & +\beta_{2} \text { wage }^{2}+\beta_{3} \text { Overtime } 2+\beta_{4} \text { Overtime3 } \\
& +\beta_{5} \text { Overtime } 4+\beta_{6} \text { Security } 2+\beta_{7} \text { Transfer2 } \\
& +\beta_{8} \text { Relocation } 2
\end{aligned}
$$

With the exception of the wage variables, the other variables are indicator variables. ${ }^{10}$

30. The significance and magnitude of the $\beta$ coefficients indicate the relative importance of those attributes that statistically influence respondent job preference. The marginal rate of substitution of any two variables represents the trade-offs made between the two attributes, and in particular, trade-offs between wage and another attribute provide estimates of willingness to pay (WTP) for the particular characteristic. WTP is the maximum amount of money individuals are willing to forfeit in order to obtain the particular characteristic of the job. In simple linear models, WTP measures are calculated as the (negative of the) ratio of wage and another parameter estimates, holding all else constant. However, as the equation (5) has wage square in the model, the WTPs depends on the level of wage. As an example, a simplified model with only Wage and Overtime is shown below. WTP for Overtime measures the change in wage that compensates a change in Overtime such that utility remain constant. ${ }^{11}$ As shown in the last term, the WTP depends on wage level.

\footnotetext{
${ }^{10}$ This specification and what follows ignores the possibility of interaction terms among job attributes. In the econometrics we investigated possible interaction effects but failed to find anything that significantly changes the message from the linear model. Hence, we focus on the linear case.

${ }^{11}$ In models that are linear in wage, WTP for an improvement in job conditions equals willingness to accept (WTA) a higher wage for an equivalent reduction in job conditions. However, in the quadratic model, income effects mean that WTP and WTA are not the same. More specifically $\beta_{2}<0$ implies that WTP $<$ WTA. To simplify terminology, we will stick to the WTP label for the rest of the paper.
} 
(Simplified Example)

$$
\begin{gathered}
\mathrm{V}=\beta_{1} \text { Wage }+\beta_{2} \text { Wage }^{2}+\beta_{3} \text { Overtime } \\
\mathrm{WTP}=\mathrm{d} \text { Wage } / \text { d Overtime }=-\beta_{3} /\left[\beta_{1}+2 \beta_{2} \text { Wage }\right]
\end{gathered}
$$

Note that though $\beta$ is not identified, because $\lambda \beta$ is identified, WTP measures can be identified, as $\lambda$ in the numerator and the denominator cancels out.

31. Though in this example overtime is treated as a differentiable variable, in practice overtime levels are discrete, as are most of the other variables in the utility equation with the exception of the wage variable. If the utility function was linear in wage then this would not be an issue, but when there is a quadratic term, the WTP estimate obtained via the derivative approach may be biased. Treating them as discrete instead yields a quadratic equation in WTP that must be solved:

$$
\begin{aligned}
\beta_{1} \text { Wage }+ & \beta_{2} \text { Wage }^{2}+\beta_{3} \text { Overtime } \\
& =\beta_{1}(\text { Wage-WTP })+\beta_{2}(\text { Wage }- \text { WTP })^{2}
\end{aligned}
$$

32. In addition to the variables related to the five attributes in the choice experiment, some socio-demographic characteristics of the decision maker, such as gender, age, marital status, education, having children, and income; might be important to an explanation of an individual's job choice. However, if we just add those socio-demographic variables, they drop out of equation (5). Thus, to identify differences in preferences arising from the decision maker's characteristics we need to interact socio-demographic characteristics with the nonwage variables. In the result sections, we investigate various specifications with interaction terms in which some important socio-demographic variables are interacted with other nonwage variables. The marginal utility of the individual with the particular characteristics $q$ then becomes

$$
\beta_{\mathrm{k}}=\beta_{\mathrm{ko}}+\beta_{\mathbf{k}^{\prime} \mathrm{q}} \text { for } \mathrm{k}>2
$$

Where $q$ is a vector of socio-demographic variables and $\beta_{\mathbf{k}}$ is a vector of associated parameters. For example, if $\mathrm{q}=$ (female, no_children), where female $=1$ if the individual is female and female $=0$ if the individual is male, and no_children $=1$ if the individual has no children and no_children $=0$ if the individual has at least one child, then

$$
\beta_{\mathbf{k}}=\beta_{\mathbf{k} 0}+\beta_{\mathbf{k} 1} \text { female }+\beta_{\mathbf{k} 2} \text { no_children for } \mathrm{k}>2
$$




\section{BASIC INFORMATION ABOUT THE CHOICE EXPERIMENT}

33. The experiment was conducted by an established online survey company in late December 2017 through early January 2018. The survey company uses a panel of signed up potential respondents, and an invitation to participate in the survey was sent to our targeted subjects who are Japanese, aged between 20 and 59 and who have at least one job experience. As it is the case for online surveys in general in Japan, it is difficult to collect responses from young people. To deal with this, the online survey company collects responses from the 20s-30s group and the 40s-50s group separately, so as to balance the numbers of responses from the two groups. In the effort not to miss the information of younger cohorts, the survey company takes extra measures (e.g. more survey invitations sent out to the signed up potential respondents) to secure number of those responses, probably leading to the different patterns of age-participation relationships as that of older cohorts.

34. There are effective answers from 1,046 respondents in total. The panel is diverse by age, gender etc., but not necessarily representative (see Table 3). In particular, in an effort to match the number of young (the 20s-30s group) to old (the 40s-50s group) in the sample, the survey company collected relatively more people in the 35-39 age group compared to the 2024 group. Though the sample may not be representative, it still covers the current and potential labor force, which is the focus of the study. More details about each characteristics of respondents are described in the following.

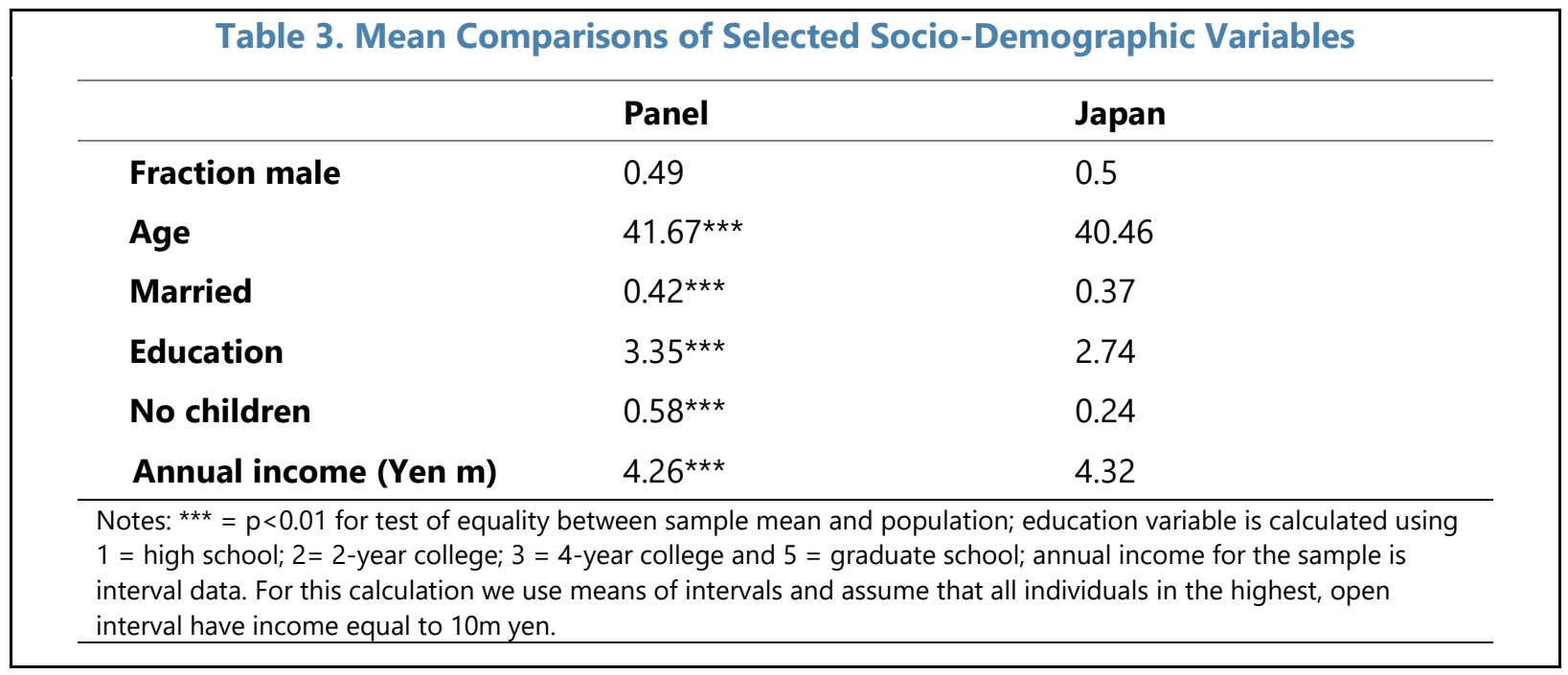

35. The sample is notably more educated than the national distribution, as 48 percent are four-year university graduates whereas the national figure is 26 percent (2012). The distribution across prefectures shows a higher frequency in the Kanto-region (Tokyo, Kanagawa, and Saitama), as well as Aichi and Osaka prefectures, compared to the national distribution. The four largest cities are contained in these prefectures, so the sample seems slightly biased away from the most rural areas. Nevertheless, we have responses from all 47 prefectures. 
36. Equivalent measurements of individual annual income nationwide are not available, so instead, survey by the National Tax Agency was used as comparison. ${ }^{12}$ Though the share of high earners in the panel is slightly higher than the national comparison, because of people who reported zero income, the panel has a lower mean income than the national mean as reported in the above table, though this may simply be an artefact of how we chose the upper limit for income in our estimation. The panel also has a slightly higher share of regular employees than non-regular employees, and the ratio is about the same as the national distribution which in 2012 was 7:3. The sample has more housewives/ husbands and less students than national distribution, but the ratio of total working people to non-working people (including both housewives/husbands and students) are almost the same as the national distribution: 8:2.

37. Before running the econometric models, we conducted various checks to see if the stated choice data is trustworthy and meaningful as a source of information. For example, high drop-out rates can be a sign that the survey is confusing or boring. The number of dropouts for the four choice set groups was 35, 29,36, and 46, resulting the ratio of drop-out to initial respondents in percentage to be 10,9,10, and 13 respectively. The drop-out rates seem to be reasonably low and in line with results elsewhere.

38. It is possible that respondents completely ignore some of the less relevant variables for them when making decisions. One question asking whether they ignore any of the variables was included in the survey after the stated choice questions. It shows 45 percent of respondents did not ignore any of the variables when making decisions and considered all variables in all the choice sets they were asked. Among respondents who ignored at least one variable when making decisions, security and transfer are more often ignored, while wage, overtime and relocation are much less frequently ignored.

39. In another question, respondents were asked, "how much additional wage would you like in order for you to switch to a job with 45 hours or more overtime per month?" Most respondents asked for a large increase. 46 percent respondents said they need to get at least 3 million yen more annual wage than current job to accept 45 hours or more overtime per month, while 35 percent say they would not accept it with pay increase of 3 million yen or less. This result is consistent with the high WTP estimates we get for the empirical analysis in the following section. In the survey after the stated choice questions, there are questions asking how realistic and applicable the hypothetical job choice situations were for them. On average, respondents thought the hypothetical job choice situations are realistic and situations well apply to them. ${ }^{13}$ Overall therefore we conclude that the results of the checks are supportive of the coherence and usefulness of the data.

\footnotetext{
${ }^{12}$ Statistical Survey of Actual Status for Salary in the Private Sector in 2016 conducted by National Tax Agency: https://www.nta.go.jp/english/index.htm

${ }^{13}$ In reality, some individual job choices are not resulting from his/her sole decisions but rather from decisions of a household as a single unit which might not be well assessed by individual level surveys. However, Beninger, Laisney and Beblo (2007) support the validity of our analysis as they illustrate that married women's
} 


\section{RESUlts OF THE CHOICE EXPERIMENT}

40. Recall that the dependent variable is the ranking of the particular job (3 indicating the best job, 2 indicating the second-best job, and 1 indicting the worst job) in the choice set. The independent variables include the five attributes and some socio-demographic characteristics of the respondents as described in Section 4.

\section{A. Main Effects and the WTPs}

41. Table 4 shows the simplest, benchmark model (Model 1) with no interaction and no socio-demographic variables. All coefficients have the expected sign and are significant at 1 percent except the low level of overtime (Overtime2, which captures the overtime amount of less than 15 hours per month) with 5 percent significance level. A negative coefficient on the square of wage indicates diminishing marginal utility of income and implies that WTP is increasing in the wage rate.

\begin{tabular}{|c|c|}
\hline \multicolumn{2}{|c|}{ Table 4. A Benchmark Econometric Model (Model 1) } \\
\hline Variables & Benchmark Model \\
\hline \multirow[t]{2}{*}{ Wage } & $1.350^{\star * \star}$ \\
\hline & $(0.0670)$ \\
\hline \multirow[t]{2}{*}{ Wage squared } & $-0.0773^{* \star *}$ \\
\hline & $(0.00510)$ \\
\hline \multirow[t]{2}{*}{ Overtime2 } & $-0.0665^{* *}$ \\
\hline & $(0.0323)$ \\
\hline \multirow[t]{2}{*}{ Overtime3 } & $-0.514^{* * *}$ \\
\hline & $(0.0351)$ \\
\hline \multirow[t]{2}{*}{ Overtime4 } & $-1.327^{* \star *}$ \\
\hline & $(0.0500)$ \\
\hline \multirow[t]{2}{*}{ Security2 } & $-0.324^{\star \star \star}$ \\
\hline & $(0.0313)$ \\
\hline \multirow[t]{2}{*}{ Transfer2 } & $-0.905^{\star * *}$ \\
\hline & $(0.0325)$ \\
\hline \multirow[t]{2}{*}{ Relocation2 } & $-0.307^{* * *}$ \\
\hline & $(0.0221)$ \\
\hline Observations & 25,104 \\
\hline Number of groups & 8,368 \\
\hline \multicolumn{2}{|c|}{$\begin{array}{l}\text { Robust standard errors clustered at individual level in parentheses, } \\
{ }^{* \star \star} p<0.01,{ }^{* \star} p<0.05,{ }^{*} p<0.1 \text {. }\end{array}$} \\
\hline \multicolumn{2}{|c|}{$\begin{array}{l}\text { Note: The table shows the coefficients of the rank-ordered logit regression to assess the importance of the factors influencing } \\
\text { workers' job choice decisions. The dependent variable is the ranking of the particular job in the choice set ( } 3 \text { indicating the } \\
\text { best job, } 2 \text { indicating the second best job, and } 1 \text { indicting the worst job). The independent variables include the five attributes } \\
\text { described in Section } 3 \text {. This model is the simplest model with no interaction and no socio-demographic variables, and the } \\
\text { reported coefficients are used to calculate WTPs in Table } 5 .\end{array}$} \\
\hline
\end{tabular}

labor supply is better predicted using the collective framework (which accounts for multiple decision makers within a household) rather than using the common unitary approach of economic household models. 
42. We calculate WTP in million yen based on these estimated parameters (see Table 5). ${ }^{14}$ Recall that because Model 1 has wage squared, WTPs depend on level of wage. For example, the WTP for Overtime2 for wage 3 million yen can be interpreted as people are willing to pay 0.075 million yen to avoid Overtime2 (15 hours or less overtime). All WTPs in Table 5 are significant at 1 percent in all wage levels, except WTPs for Overtime2 with 1-5 percent significance level depending on the level of wage. ${ }^{15}$ Table 5 shows that people very much dislike Overtime4 (45 hours or more overtime per month). For example, people with an annual 3-million-yen wage are willing to pay 1.3 million yen, nearly half of their annual wage, in order to avoid such overtime, and people in their highest wage group (8 million yen) are willing to pay $3.5 \mathrm{~m}$ yen to avoid 45 hours or more overtime. People are also willing to pay high amount in order to avoid transfer, ranging from 0.94 to 2.76 million yen depending on their wage level. ${ }^{16}$

\begin{tabular}{|c|c|c|c|c|c|c|}
\hline $\begin{array}{c}\text { Model } 1 \\
\text { WTP }\end{array}$ & $3 M$ yen & 3.5M yen & $4 M$ yen & $6 M$ yen & $7 M$ yen & $8 \mathrm{M}$ yen \\
\hline Overtime2 & $0.075^{* *}$ & $0.082^{* \star}$ & $0.090^{* *}$ & $0.153^{* *}$ & $0.232^{\star \star \star}$ & $0.447^{\star \star \star}$ \\
\hline Overtime3 & $0.553^{* * *}$ & $0.600^{* * *}$ & $0.656^{\star \star \star}$ & $1.023^{\star \star *}$ & $1.371^{\star \star \star}$ & $1.943^{* * *}$ \\
\hline Overtime4 & $1.340^{* * *}$ & $1.441^{* * *}$ & $1.556^{\star \star *}$ & $2.228^{* * *}$ & $2.755^{\star * *}$ & $3.470^{* * *}$ \\
\hline Security 2 & $0.355^{* * *}$ & $0.386^{* * *}$ & $0.424^{* * *}$ & $0.681^{* * *}$ & $0.948 * * *$ & $1.439 * * *$ \\
\hline Transfer 2 & $0.944^{* * *}$ & $1.019 * * *$ & $1.107^{\star \star *}$ & $1.645^{\star * *}$ & $2.101^{* * *}$ & $2.763^{* * *}$ \\
\hline Relocation2 & $0.336^{* * *}$ & $0.366^{* * *}$ & $0.402^{* * *}$ & $0.648^{* * *}$ & $0.905^{\star * *}$ & $1.386^{* * *}$ \\
\hline \multicolumn{7}{|c|}{$\begin{array}{l}{ }^{\star \star *} p<0.01,{ }^{\star \star} p<0.05,{ }^{*} p<0.1 \\
\text { Note: The table shows the WTPs calculated from the regression results from the simplest model with no interaction reported } \\
\text { in Table 4. As seen in the table, WTP depends on the level of wage. This is because I assume in the model that while the } \\
\text { value of non-wage attribute (e.g. not having overtime) is uniform across wage groups, marginal utility of wage is decreasing } \\
\text { in wage. }\end{array}$} \\
\hline
\end{tabular}

${ }^{14}$ When we estimate these numbers using the derivative we get similar patterns of significance and values that are similar for most of the coefficients. The biggest divergence is for overtime 4 where in some cases the derivative method yields an estimate for WTP which is bigger than income. For example, when income is $8 \mathrm{~m}$ yen, the estimate is $11.7 \mathrm{M}$ yen

${ }^{15}$ To compute the standard errors, the delta method is used, Dowd et al. (2014).

16 The independence of irrelevant alternatives (IIA) assumption means that, all else being equal, a person's choice between two alternative outcomes does not depend on the availability or attributes of the other alternatives. IIA is an assumption of the ranked logit model (Hensher, Rose and Greene 2005). With an unlabeled experiment, a failure of the IIA assumption may come about because the number of alternatives or the ranking procedure has affected the evaluation of the alternatives or the scale of the noise variable. When we test the IIA assumption using a standard approach - in which the estimated coefficients of the full model are compared with the ones from restricted models in which the worst option is dropped, (Cheng and Long 2007) in general we reject the IIA assumption. However, what matters to the economic interpretations of the results are the robustness of WTP estimates and these are not significantly different when the restricted model used. We also conduct similar tests when the model allows for interaction with socio-demographic variables and again we find no evidence that the restricted model produces systematically different WTP figures compared to the unrestricted model. 


\section{B. WTPs Based on Different Socio-Demographic Characteristics ${ }^{17}$}

43. It is perhaps more interesting to see how job trade-offs vary with circumstances, so we calculate WTPs based on an extended model (Model 2 in Appendix 2) with interaction terms to see the differences in WTPs arising from specific socio-demographic characteristics of respondents. In Model 2, we interact non-wage job characteristics with a female dummy, which takes value 1 if the respondent is female and 0 otherwise; and no_children dummy, which takes value 1 if the respondents has no children and 0 otherwise; and female and no_children interaction (female * no_children), which takes value 1 if the respondents is female and has no children and zero otherwise; and separately we interact non-wage job characteristics with age_cohort dummies (30s, 40s and 50s) and with a dummy for whether the person has completed a 4 year college degree. ${ }^{18}$ In the model, therefore, the baseline is male in their 20s with children and no degree. Table 6 below shows the WTP estimation using the parameters from Model 2. Hereafter, for simplicity, we fix wage at 3 million yen, and age cohort at 30s and the person has a degree, but technically, it is possible to calculate WTPs for all six wage levels and for each age cohort (20s, 30s, 40s and 50s). All cases refer to people in their 30s with 3 million yen in wages. The left most column in Table 6, "base" refers to the case "male, with children". The "female" column refers to the case, "female, with children." The "no children" column represents the case, "male, without children." And finally, the "female* no_children" refers to the case "female, without children."

44. The table is informative in several aspects. First, when interaction terms are included, some WTP values become statistically insignificant. For example, men with children are not WTP for improved security or to avoid relocation. It suggests that men in such circumstances have a relatively elastic supply of some aspects of their labor.

\footnotetext{
${ }^{17}$ Current income may also affect WTP either through a status quo effect, for example, or perhaps because people select into their current job based on their preferences for life-style and individuals with low income are therefore those who value flexibility over income. When we investigate this using an interactive dummy for above mean income we find that generally people with a higher current income have a higher WTP for flexibility though in most cases the differences are not significant. One place we find differences is that higher income individuals - both men and women - put much less value on job security relative to lower income respondents. This may reflect their confidence about their ability to find well-paid alternatives.

${ }^{18}$ We do not distinguish between married and unmarried respondents. Having children outside of marriage is rare in Japan (Ministry of Health Labour and Welfare 2010), so most of our respondents who have children are also married. When we run a model which includes interactive dummies for marriage we get similar results to those reported in Table 6.
} 


\begin{tabular}{|c|c|c|c|c|}
\hline \multicolumn{5}{|c|}{$\begin{array}{l}\text { Table 6. WTP Estimation for Wage } 3 \text { Million Yen in their 30s } \\
\text { (In million yen) }\end{array}$} \\
\hline \multicolumn{5}{|c|}{ Model 2 (4-Year College-Educated) } \\
\hline WTP & Base & Female & No_children & Female*no_children \\
\hline Overtime2 & 0.092 & $0.216^{\star \star \star}$ & 0.149 & $0.050 * * \star$ \\
\hline Overtime3 & $0.330^{\star * *}$ & $0.756^{\star * *}$ & $0.558^{* * *}$ & $0.753^{* * *}$ \\
\hline Overtime4 & $0.955^{\star * *}$ & $1.676^{\star * *}$ & $1.319 * * *$ & $1.616^{* * *}$ \\
\hline Security 2 & 0.095 & $0.421^{\star \star \star}$ & $0.327^{\star \star \star}$ & $0.372^{\star * \star}$ \\
\hline Transfer 2 & $0.821^{\star *}$ & $1.337^{\star * *}$ & $0.930 * * *$ & $1.313^{* * *}$ \\
\hline Relocation2 & $0.208^{* \star *}$ & $0.540 * * \star$ & $0.621^{\star \star *}$ & $0.630 * * *$ \\
\hline \multicolumn{5}{|c|}{ Model 2 (Less Than 4-Year College) } \\
\hline WTP & Base & Female & No_children & Female*no_children \\
\hline Overtime2 & 0.049 & $0.174^{* *}$ & 0.106 & 0.007 \\
\hline Overtime3 & $0.236^{* * *}$ & $0.668^{* * *}$ & $0.467^{* * *}$ & $0.665^{* * *}$ \\
\hline Overtime4 & $0.777^{* * *}$ & $1.515^{\star * \star}$ & $1.151^{* * *}$ & $1.454^{* * *}$ \\
\hline Security 2 & 0.059 & $0.386^{* * *}$ & $0.292^{* * *}$ & $0.337^{\star * *}$ \\
\hline Transfer 2 & $0.616^{* * *}$ & $1.148 * \star \star$ & $0.719 * * *$ & $1.123^{* * *}$ \\
\hline Relocation2 & -0.070 & $0.277^{\star * *}$ & $0.361^{* * *}$ & $0.370^{* * *}$ \\
\hline \multicolumn{5}{|c|}{$\begin{array}{l}{ }^{* \star *} p<0.01,{ }^{* *} p<0.05,{ }^{*} p<0.10 \\
\text { Note: This table shows the WTPs calculated from the regression results from the model with some interaction terms. It } \\
\text { means that non-wage attributes are interacted with dummy variables of gender, having no children, gender }{ }^{\star} \text { no_children, } \\
\text { and education. For simplicity, it shows only for the case of annual wage } 3 \text { million yen. Each cell shows the total WTP for the } \\
\text { attribute (e.g. Overtime } 2 \text { ) for an individual with certain characteristics (e.g. Female with no children). For example, the right } \\
\text { upper corner cell for the } 4 \text {-year college educated case can be interpreted that female with no children are willing to pay } \\
0.05 \text { million yen to avoid } 0-15 \text { hours of overtime (Overtime 2). }\end{array}$} \\
\hline
\end{tabular}

45. Second, the sign of WTPs for transfer may be counterintuitive for some people, as WTPs for transfer are all positive, meaning respondents dislike transfer, at any given respondent characteristics. Some people may like to experience different works for their career development or simply as a taste for variety. While that explanation may be right for some people, this empirical result (positive WTP) holds true for all those specified individual characteristics. And moreover, the distaste for transfer was observed across different education levels. Finally, from Table 6, we can see that gender and the presence of children might influence level of WTPs for each attribute. It appears for example that women are WTP more than men to avoid relocation, transfer and extreme overtime.

46. Table 7 follows up on this and reports the comparison of WTP measures across gender and family structure. We report only the tests for the groups with higher levels of education since the results for the other group are so similar. The top part of Table 7 shows gender differences in WTP, calculated as male minus female. Positive (negative) sign indicates higher WTP for male (female) for all attributes. It shows that women tend to have higher WTPs in absolute value than men for most of the attributes, for both with children 
groups and without children groups. ${ }^{19}$ This findings add to the observations found in existing studies, where women in general have higher WTP for flexible work arrangements than men (Mas and Pallais (2017); Wiswall and Zafar (2018) ).

\begin{tabular}{|c|c|c|}
\hline \multicolumn{3}{|c|}{$\begin{array}{l}\text { Table 7. Testing Differences in WTP for 4-Year College or Higher Respondents } \\
\text { (Model 2) }\end{array}$} \\
\hline \multicolumn{3}{|c|}{ Gender Differences in WTP (Male-Female) } \\
\hline WTP & With children & No children \\
\hline Overtime2 & -0.12 & 0.10 \\
\hline Overtime3 & $-0.43^{* * *}$ & $-0.20^{* *}$ \\
\hline Overtime4 & $-0.72^{\star \star \star}$ & $-0.30 * \star \star$ \\
\hline Security 2 & $-0.33^{* \star *}$ & -0.04 \\
\hline Transfer 2 & $-0.52^{* \star *}$ & $-0.39 * * \star$ \\
\hline Relocation2 & $-0.33^{* * *}$ & -0.04 \\
\hline \multicolumn{3}{|c|}{ Differences in WTP by Presence of Children (With Children- Without Children) } \\
\hline & Male & Female \\
\hline Overtime2 & -0.06 & 0.17 \\
\hline Overtime3 & $-0.23^{* *}$ & 0.002 \\
\hline Overtime4 & $-0.36^{\star \star *}$ & 0.06 \\
\hline Security 2 & $-0.41^{* * *}$ & -0.09 \\
\hline Transfer 2 & -0.09 & 0.02 \\
\hline Relocation2 & $-0.23^{* * *}$ & 0.05 \\
\hline
\end{tabular}

47. The lower part of Table 7 shows differences in WTP by the presence of children, calculated as with children minus without children. It suggests that men without children have higher absolute WTPs than men with children. On the other hand, when comparing between the two female groups, there are no statistically significant differences. This finding may seem counter-intuitive, as we expect parents tend to value flexible work arrangement more to take care of their children. However, having children may raise the marginal utility of income as well as the marginal utility of leisure, so it is entirely reasonable that labor supply may become more unresponsive to changes in working conditions in the presence of children. Viewed this way, the results suggest that for women, the two effects cancel out, while for men the rise in the marginal utility of income dominates. ${ }^{20}$

\footnotetext{
${ }^{19}$ As an extension of the study, it would be interesting to see if similar gender differences in WTP to avoid overtime are observed in other countries, as Japanese male workers on average work three to five hours longer per week than the averages for German and British male workers (Kuroda and Yamamoto (2013).

${ }^{20}$ Another possible explanation is that men with higher tolerance to overtime etc. have a higher possibility of having children than men with lower tolerance, while whether a woman has children or not does not depend on her job preferences.
} 
48. While the No_children dummy in the model only captures the binary effect of presence of children, it might be the case that raising children have both fixed-cost and variable-costs for parents and it might be worth separating the two effects. By fixed-cost, we mean the cost arising once having a first child compared to zero children, and it is assumed to remain the same regardless of number of children or age of children. Once having a child, the life is never the same as before, with a lot more to worry about and a lot more to enjoy. On the other hand, variable-cost is defined as a marginal cost arising from having more children or having older children. It is often said that having two children does not cost as much as the double the cost of raising one child. Also, it can be expected that costs of raising one more infant and costs of raising one more pre-school child must be different. To see these differences, we run two other extended models with categorical dummy variables of 1) total number of children and 2) age of the youngest children in the family. Those children dummies are interacted with non-wage attribute variables and with gender to see differences between men and women (results omitted here). There are no clear additional patterns neither across different number of children nor across different age of the youngest children in the family for both genders, suggesting that the results reported in Table 7 are not simply the consequence of the specification we use.

\section{GuILt EFFECTS}

49. We now turn to another behavioral angle. Not only might the socio-demographic characters of a respondent affect his/her job choice, but also his /her emotional state. Moreover, if there are gender differences in emotional state then it might be the underlying factor in gender differences in the measured WTPs. Some studies found women feel more guilt than men (Etxebarria, et al. 2009) while other studies found men and women feel about the same level of guilt, but in the different situations (Martínez, et al. 2011). We therefore included questions in the survey to explore the feelings of guilt about working and parenting. For example, "I took paid leave when my managers and colleagues are working a lot of overtime”. In all, we drafted seven items (see Table 8 which includes mean responses) to describe the situations faced by working mothers and fathers that potentially generate guilt, and asked respondents to rate the situation on five-point scale ranging from 1 (very guilty) to 5 (not at all guilty). Working men and women tend to feel stress when 1) work can interfere with family life (i.e., work-to-family conflict: WFC) and when 2) family life can interfere with work (i.e., family-to-work conflict: FWC) (Shimazu, et al. 2013). Results show that women in our sample tend to feel guiltier than men in general and the differences are statistically significant at 1 percent for all the questions. ${ }^{21}$

\footnotetext{
${ }^{21}$ Since our measurement of guilty feelings relies on self-reported subjective ratings, we cannot disaggregate gender differences into actual feeling, perception, or reporting of emotions. See for example Fischer, Kret and Broekens (2018) about gender differences in emotion perception and self-reported emotional intelligence.
} 


\begin{tabular}{|c|c|c|c|c|c|}
\hline \multicolumn{6}{|c|}{ Table 8. Mean Guilt } \\
\hline & Questions & Male & Female & $\begin{array}{l}\text { Male } \\
\text { with } \\
\text { children }\end{array}$ & $\begin{array}{l}\text { Female } \\
\text { with } \\
\text { children }\end{array}$ \\
\hline q1 & $\begin{array}{l}\text { I took paid leave when my managers and } \\
\text { colleagues are working a lot of overtime. }\end{array}$ & 3.074 & 2.760 & 2.82 & 2.535 \\
\hline $\mathrm{q} 2$ & $\begin{array}{l}\text { I left the office on time for a family event } \\
\text { when my managers and colleagues are } \\
\text { working. }\end{array}$ & 3.166 & 2.867 & 3.08 & 2.668 \\
\hline q3 & $\begin{array}{l}\text { I did not prepare healthy dinner for me and } \\
\text { my family for the entire week }\end{array}$ & 3.003 & 2.548 & 2.865 & 1.979 \\
\hline q4 & $\begin{array}{l}\text { Because I was working I missed my } \\
\text { child(ren)'s event which I had promised to go }\end{array}$ & 2.595 & 2.304 & 2.235 & 1.838 \\
\hline q5 & $\begin{array}{l}\text { I did not see my elderly parents or other } \\
\text { relatives who need care for the last one } \\
\text { month. }\end{array}$ & 2.788 & 2.427 & 2.695 & 2.274 \\
\hline q6 & $\begin{array}{l}\text { Not earning enough income to satisfy the } \\
\text { demands of my child (extra-academic } \\
\text { activities, clothes, games...) }\end{array}$ & 2.706 & 2.591 & 2.535 & 2.278 \\
\hline $\mathrm{q} 7$ & $\begin{array}{l}\text { Not being able to spend time with my child } \\
\text { when we are at home because I must perform } \\
\text { tasks that do not concern the family. }\end{array}$ & 2.798 & 2.573 & 2.600 & 2.203 \\
\hline
\end{tabular}

50. To see if the level of guilt in each item affect WTP, an extended model is run with interactions between the guilt variables and non-wage attribute variables, and include interaction effects between gender, having children and guilt. Table 9 shows WTP measures for hypothetical people with children, who differ only by guilt levels, and have an annual wage of 3 million yen and are in their 30s. The No Guilt label refers to a person rating all guilt questions as 5 (not at all guilty), while All Guilt is for a person rating all guilt questions as 1 (very guilty). It seems that person who feels guilty tends to have higher WTPs. In fact, for the individuals who feel no guilt, the WTP estimates are rarely significantly different from zero. Since, in our sample women tend to have higher guilt level than men, it might be the case that higher female WTPs we see in earlier tables are partly because of their higher guilt level. The final column of the table examines the difference in WTP between men and women for the All Guilt case. The differences are significant at the 1 percent level for most variables with the exception of Overtime2. The differences for the No Guilt case are not shown but follow a similar pattern of significance. Recall that these WTP figures are millions of yen in annual salary, so the size of the difference between men and women is also meaningful compared to the posited 3-million wage. 
Table 9. Guilt, WTP, and Gender

\begin{tabular}{|c|c|c|c|c|c|}
\hline \multirow{2}{*}{ WTP } & \multicolumn{2}{|c|}{ Male Guilt } & \multicolumn{2}{|c|}{ Female Guilt } & \multirow{2}{*}{$\begin{array}{c}\text { Difference } \\
\text { All Guilt }\end{array}$} \\
\hline & No Guilt & All Guilt & No Guilt & All Guilt & \\
\hline Overtime2 & -0.015 & 0.051 & 0.122 & 0.187 & 0.136 \\
\hline Overtime3 & -0.146 & 0.152 & 0.304 & $0.580^{* * *}$ & $0.429 * \star \star$ \\
\hline Overtime4 & 0.018 & $0.902^{\star * \star}$ & $0.795^{*}$ & $1.586^{\star \star *}$ & $0.684^{* * *}$ \\
\hline Security & -0.065 & -0.191 & 0.299 & 0.180 & $0.371^{\star * *}$ \\
\hline Transfer & -0.194 & $0.631^{* * *}$ & 0.354 & $1.114^{\star * *}$ & $0.483^{* * *}$ \\
\hline Relocation & 0.111 & 0.096 & $0.447^{*}$ & $0.432^{* * *}$ & $0.337^{\star * \star}$ \\
\hline
\end{tabular}

${ }^{* * *}=p<0.01,{ }^{* *}=p<0.05 ;{ }^{*}=p<0.10$

Note: This table shows WTP measures for hypothetical people with children, who differ only by guilt levels, and have an annual wage of 3 million yen and are in their 30s. The No Guilt label refers to a person rating all guilt questions as 5 (not feeling guilty at all), while All Guilt is for a person rating all guilt questions as 1 (feeling very guilty). The final column of the table examines the difference in WTP between men and women for the 'All Guilt' case, while 'No Guilt' case is omitted but follows the similar pattern.

51. Table 10 shows WTP to avoid Overtime 4 for a female with children, a wage of 3 million yen and in her 30s, by varying the rating scores for each guilt questions. For example, if the person only feels very guilty (rating 1) about taking paid-leave and not at all guilty (rating 5) for all the other six situations, her WTP for Overtime 4 is 0.707 million yen. From Table 10, we can see female WTP for overtime 4 is the highest when she feels guilty for canceling children's events for work, for not caring for elderly parents and for not caring for kids while at home. On the other hand, there is no significant WTP when she only feels highly guilty about leaving the office early or talking paid leave or not earning enough.

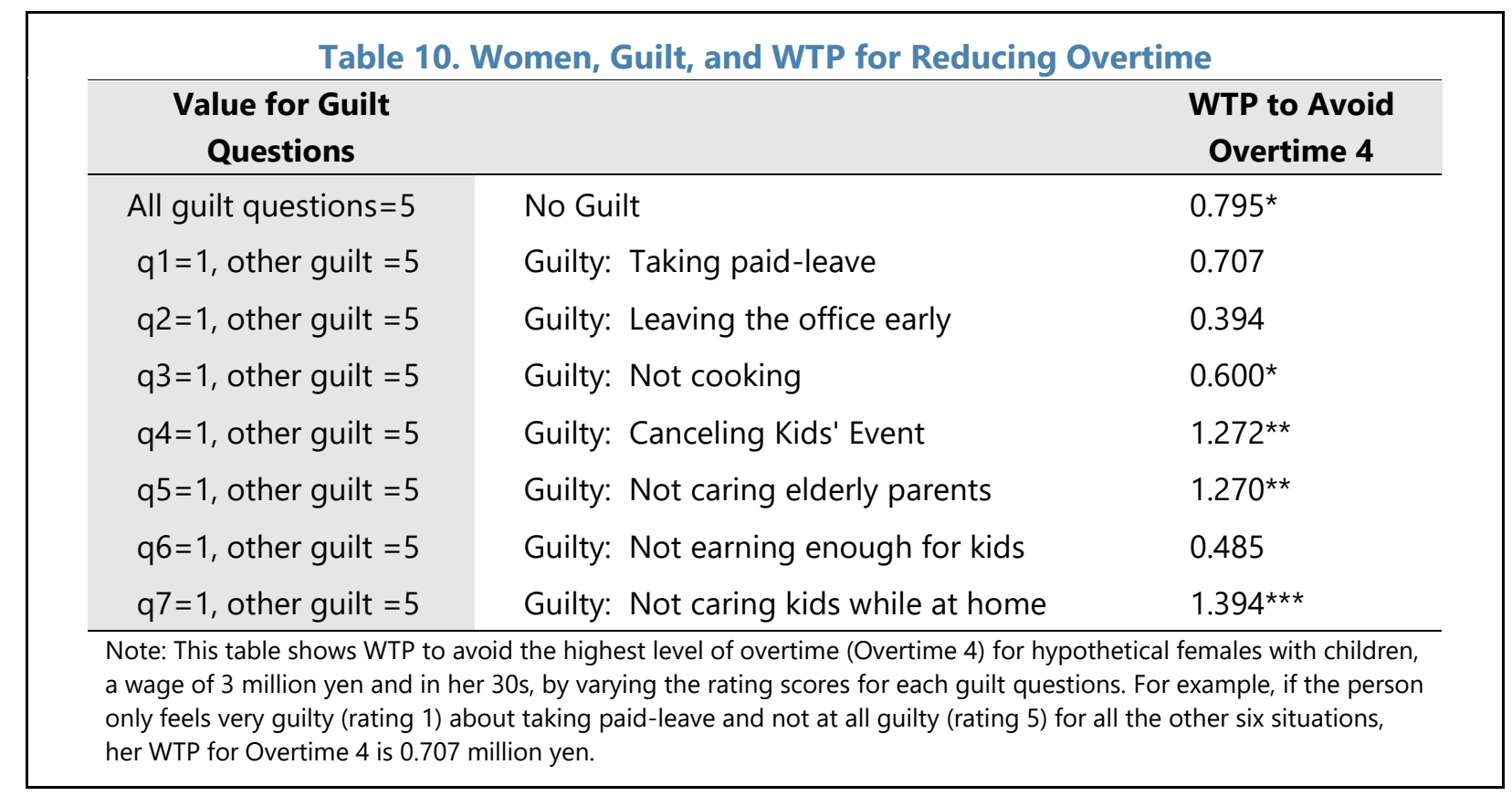


52. The above findings are interesting in two ways. First, they suggest that the higher female WTPs compared to male WTPs might be actually due to the higher likelihood of women feeling guilty compared to men, as well as the greater sensitivity of WTP to guilt for women compared to men. Second, though as discussed in earlier sections, female WTPs are mostly constant across family structure (i.e. having or not having children) or marital status, women are more prone to feel guilty and thus have higher WTPs as working mothers.

\section{Policy Implications ANd Conclusions}

53. Choice experiments are a potentially useful tool for analyzing labor market reforms in the absence of quality revealed preference data. In this paper, we use the method to investigate Japanese workers' preferences for adjustments to their working conditions. In particular, we focus on overtime, compulsory relocations, and transfers as well as job security. The results are coherent and, in general, they are precisely estimated. Our benchmark model suggests that people significantly dislike overtime (when it is more than the typical amount), job insecurity, and the possibility of intra-firm job transfer and relocation. The WTP calculation suggests that people are willing to forfeit a large portion of their wage to avoid extreme overtime and job transfers in particular. Perhaps not surprisingly, the job choice preferences seem to differ between men and women, with-children group and no-children group, and across different ages. Conditional on the annual salary, women in general have higher WTPs than men to avoid overtime, relocation, and transfer, and have a higher WTP to have more secure jobs. Men without children value flexibility more than men with children, but for women there are no major differences between the responses of women with and without children.

54. Guilt plays a role in the WTP and particularly in the difference between male and female responses. Generally, it was found that women tend to feel guiltier about compromising home responsibilities and, conditional on the same guilt level, have higher WTPs for avoiding work responsibilities compared to men. This creates a multiplicative impact of guilt that raises the WTP for flexibility of women relative to men. These feelings of guilt amongst female respondents were higher, not just for child-related activities (such as missing school events), but also for more general home responsibilities such as cooking the dinner. In the context of Japan's ageing population, where middle-aged adults are increasingly sandwiched between responsibilities for looking after children and their elderly parents, it is also notable that women felt guiltier about not caring for parents and that WTP was especially sensitive to this factor. An implication of these findings is that policies to reduce gender gaps in labor market behavior may need to consider how feelings of guilt can be altered.

55. From the policy perspective, these results from the choice experiment imply that a limited-regular contract can be an appealing option for workers with various characteristics, especially - but not only - for women with children. While this qualitative result might have been predicted by common sense, the paper advances the argument by quantifying the 
tradeoff between wage and the non-wage job attributes. The WTP estimates reported here could be used as a guide to the most valuable areas to reform standard labor market contracts. The policy challenge, though, is to avoid the creation of new glass ceilings for women or to raise job market segmentation. Therefore, for the successful work style reform, policy makers should improve the usability of limited-regular contracts for both men and women. One way is to restrict discrimination against limited regular contracts and make sure limited contracts offer the same quality job (reflected in, for example, enough training and promotion opportunities) as regular contracts. It is also important to ensure the mobility across different contracts, so that workers are willing and able to switch from one work style to another depending on their life stage and changing needs of individual's work-life balance. 


\section{REFERENCES}

Ajzen, Icek, 1991, "The Theory of Planned Behavior," Organizational Behavior and Human Decision Process, pp. 179-211.

Baum, M., and R. Kabst, 2013, "Conjoint Implications on Job Preferences: The Moderating Role of Involvement," International Journal of Human Resource Management, pp. 24, 1393-1417.

Beggs, S., S. Cardell, and J. Hausman, 1981, "Assessing the Potential Demand for Electric Cars," Journal of Econometrics, pp. 1-19.

Beninger, Denis, François Laisney, and Miriam Beblo, 2007, "Welfare Analysis of a Tax Reform for Germany: A Comparison of the Unitary and Collective Models of Household Labour Supply," Journal of Population Economics, pp. 869-893.

Cabinet Office, 2017, "Action Plan for the Realization of Work Style Reform," Council for the Realization of Work Style Reform, March 28.

, 2014, "Tomobatarakito Setaisu No Suii (Change in the Number of Double-Income Households)," Gender Equality Bureau Cabinet Office, Accessed April 11, 2018, http://www.gender.go.jp/about_danjo/whitepaper/h26/zentai/html/zuhyo/zuhyo01-0208.html.

Caussade, S., J.D. Ortuza, L.I. Rizzi, and D.A. Hensher, 2005, "Assessing the Influence of Design Dimensions on Stated Choice Experiment Estimates," Transportation Research Part B 39, pp. 621-640.

Chang, Jae Bong, Jayson L. Lusk, and F. Bailey Norwood, 2009, "How Closely Do Hypothetical Surveys and Laboratory Experiments Predict Field Behavior?," American Journal of Agricultural Economics, Vol. 91, No. 2, pp. 518-534.

Cheng, Simon, and J. Scott Long, 2007, "Testing for IIA in the Multinominal Logit Model," Sociological Methods \& Research, Volume 35.

Chung, Chanjin, Tracy Boyer, and Sungill Han, 2011, "How Many Choice Sets and Alternatives Are Optimal? Consistency in Choice Experiments," Agribusiness, Vol. 27, pp. 114-125.

Colacelli, Mariana, and Anh Le, 2018, "Inequality in Japan: Generational, Gender, and Regional Considerations," IMF Japan Selected Issues, pp. 23-33.

Colacelli, Mariana, and Emilio Fernandez C., 2018, "Macroeconomic Effects of Japan's Demographics: Can Structural Reforms Reverse Them?," IMF Working Paper, $\mathrm{WP} / 18 / 248$.

de Bekker-Grob, Esther W., Mandy Ryan, and Karen Gerard, 2012. "Discrete Choice Experiments in Health Economics: A Review of the Literature." Health Economics 21.2, pp. 145-172. 
DeShazo, J.R., and German Fermo, 2002, "Designing Choice Sets for Stated Preference Moethods: The Effects of Complexity on Choice Consistency," Journal of Environmental Economics and Management 44, pp. 123-143.

Dowd, Bryan, William Greene, and Edward Norton, 2014, "Computation of Standard Errors," Health Services Research, pp. 731-750.

Ekeland, Ivar, James J. Heckman, and Lars Nesheim, 2004, "Identification and Estimation of Hedonic Models," Journal Political Economy, 112, No. S1, pp. S60-S109.

Etxebarria, Itziar, M. José Ortiz, Susana Conejero, and Aitziber Pascual, 2009, "Intensity of Habitual Guilt in Men and Women: Differences in Interpersonal Sensitivity and the Tendency towards Anxious-Aggressive Guilt," The Spanish Journal of Psychology.

Fischer, A.H., M.E. Kret, and J. Broekens, 2018, "Gender Differences in Emotion Perception and Self-Reported Emotional Intelligence: A Test of the Emotion Sensitivity Hypothesis," PLoS ONE 13(1), e0190712.

Heckman, James J., Rosa L. Matzkin, and and Lars Nesheim, 2010, "Nonparametric Identification and Estimation of Nonadditive Hedonic Models," Econometrica 78, No. 5, 1569-1591.

Hensher, David A, 2010, "Hypothetical Bias, Choice Experiments and Willingness to Pay," Transportation Research Part B: Methodological, Volume 44, Issue 6, July 2010, pp. $735-752$.

Hensher, David A., John M. Rose, and William H. Greene, 2005, Applied Choice Analysis A Primer, New York: Cambridge University Press.

Hole, Arne Risa, 2015, "DCREATE: Stata Module to Create Efficient Designs for Discrete Choice Experiments," Statistical Software Components S458059, Boston College Department of Economics, Revised 25 Aug 2017.

Imano, Koichiro, 2012, Seishain Shometsu Jidai No Jinji Kaikaku (HR Reform in the Age of Disappearance of Regular Employees), Tokyo, Japan: Nikkei Publishing.

International Monetary Fund, 2018, "Japan: 2018 Article IV Consultation Staff Report."

Johnson, F. Reed, Emily Lansar, Marshall. Deborah, Vikram Kilambi, Axel Muhlbacher, Dean A Regier, Brian W. Bresnahan, Barbara Kanninen, and John F.P. Bridges, 2013, "Constructing Experimental Designs for Discrete-Choice Experiments: Report of the ISPOR Conjoint Analysis Experimental Design Good Research Practices Task Force," Value in Health, pp. 3-13.

Kanemoto, Yoshitsugu, and Bentley MacLeod, 1991, "The Theory of Contracts and Labor Practice in Japan and the United States," Managerial and Decision Economics, pp. 159-170. 
Kume, Koichi, Fumio Otake, and Kotaro Tsuru, 2014, "Tayoka Suru Seiki Hiseiki Rodosha No Shugyo Kodo To Ishiki RIETI Web Anke-To Chosa No Gaiyo (Employment Behavior and Consciousness of Diversified Regular and Non-regular Workers, Outline of the RIETI Web Survey)," RIETI Policy Discussion Paper Series, 14-P003.

Kuroda, Sachiko, and Isamu Yamamoto, 2013, "Wage Premiums for Firms' Work-Life Balance Practice: Evidence from Japanese Matched Firm-Worker Data (in Japanese)," RIETI Discussion Paper Series, 13-J-004.

Lagarde, M, and D Blaauw, 2009, "A Review of the Application and Contribution of Discrete Choice Experiments to Inform Human Resources Policy Interventions," Human Resources for Health.

Martínez, Pilar, J María Carrasco, Gonzalo Aza, Angeles Blanco, and Isabel Espinar, 2011, "Family Gender Role and Guilt in Spanish Dual-earner Families." Sex Roles, pp. $813-826$.

Mas, Alexandre, and Amanda Pallais, 2017, "Valuing Alternative Work Arrangements," American Economic Review, pp. 3722-3759.

Meyerhoff, Jürgen, Malte Oehlmann, and Priska Weller, 2015, "The Influence of Design Dimensions on Stated Choices in an Environmental Context," Environ Resource Econ, 61, pp. 385-407.

Miake, Naoko, 2017, "Japan's Lifetime Employment and Gender Inequality," IMF Japan Selected Issues, pp. 31-36.

Ministry of Economy Trade and Industry, Japan, 2006, "Survey for Basic Policy Committee of Industrial Structure Council."

Ministry of Health Labour and Welfare, 2010, "Shusseini Kansuru Tokei (Birth Statistics)."

Morikawa, Masayuki, 2010, "Koyo Hosho To Wa-Ku Raihu Baransu Hosho Chingin Kakusa No Shiten Kara (Insecurity of Employment and Work-Life Balance: From the Viewpoint of Compensating Wage Differentials)," RIETI Discussion Paper Series, 10-J-042.

Oehlmann, Malte, Jürgen Meyerhoff, Petr Mariel, and Priska Weller, 2017, "Uncovering Context-Induced Status Quo Effects in Choice Experiments," Journal of Environmental Economics and Management, Volume 81, pp. 59-73.

Rabiee, Fatemeh, 2004, "Focus-Group Interview and Data Analysis," Proceedings of the Nutrition Society, pp. 655-660.

RIETI, 2015, "Heisei 26 Nendo Seishain Hiseishain No Tayou Na Hatarakikata To Ishiki Ni Kansuru Web Chosa (Web Survey on Various Working Styles and Thoughts of Regular and Non-regular Workers in FY 2014)." 
, 2012, "Jinteki Shihon Keisei To Wa-ku Raihu Baransu Ni Kansuru Kigyo Jugyoin Chosa (Corporate Employee Survey on Human Capital Formation and Work-Life Balance)."

Rosen, Sherwin, 1974, "Hedonic Prices and Implicit Markets: Product Differentiation in Pure Competitio,." Journal of Political Economy, 82(1), pp.34-55, 82(1), 34-55.

Sakai, Tadashi and Miyazato, Naomi, 2014, "Who Values the Family-Friendly Aspects of a Job? Evidence from the Japanese Labour Market," The Japanese Economic Review, 65(3), pp. 397-413.

Sato, Hiroki, Hiroyuki Fujimura, and Atsushi Yashiro, 2007, Atarashii Jinji Romu Kanri, 3rd Ed., (Contemporary Human Resource Management), Tokyo, Japan: Yuhikaku Publishing.

Shimazu, Akihito, Kazumi Kubota, Arnold Bakker, Eva Demerouti, Kyoko Shimada, and Norito Kawakami, 2013, "Work-to-Family Conflict and Family-to-Work Conflict among Japanese Dual-earner Couples with Preschool Children: A SpilloverCrossover Perspective," Journal of Occupational Health.

Sivey, P., A. Scott, J. Witt, C. Joyce, and J. \& Humphreys, 2012, "Junior Doctors' Preferences for Specialty Choice," Journal of Health Economics, 31(6), pp. 813-823.

Steinberg, Chad, and Masato Nakane, 2012, "Can Women Save Japan?," IMF Working Paper, WP/12/248.

Swait, Joffre, and Wiktor Adamowicz, 2001, "Choice Environment, Market Complexity, and Consumer Behavior: A Theoretical and Empirical Approach for Incorporating Decision Complexity into Models of Consumer Choice," Organizational Behavior and Human Decision Processes, pp. 141-167.

Toda, Akihito, 2015, "Gentei Seishain No Jittai Kigyo Kibo Betsu Ni Okeru Chingin Manzokudo No Chigai (Actual Conditions of Limited-regular Employees:

Differences in Wages and Satisfaction levels by Company Size )," Monthly Journal of The Japan Institute for Labour Policy and Training.

Train, E. Kenneth, 2003, Discrete Choice Methods with Simulation, Cambridge University Press.

Tsuru, Kotaro, 2014, Gentei Seishain Kara Nihonjin No Hatarakikata Wo Kaeru (Change the Way Japanese People Work from Limited Regular Employees), December 11, Accessed April 11, 2018, https://www.rieti.go.jp/jp/papers/contribution/tsuru/26.html.

Tsuru, Kotaro, Koichi Kume, Fumio Otake, and Hiroko Okudaira, 2013, "Hiseikirodosha Kara Mita Hosho Chingin, Fuanteikoyo, Anmokutekina Seishain Kosoku To Chingin Puremiamu No Bunpu (Compensating Wage Differential Seen by Non-regular Workers, Unstable Employment, and Distribution of Wage Premium for Regular Workers)," RIETI Discussion Paper, 13-J-003. 
Wiswall, Matthew, and Basit Zafar, 2018, "Preference for the Workplace, Investment in Human Capital, and Gender," The Quarterly Journal of Economics, pp. 457-507.

Yamada, Hisashi, 2017, Doitsurodo Doitsuchingin No Shogeki (Shock of Equal Pay for Equal Work), Tokyo, Japan: Nikkei Publishing.

Yamada, Ken, and Daiji Kawaguchi, 2015, "The Changing and Unchanged Nature of Inequality," The Journal of Economic Inequality.

Yasui, kengo, Shinpei Sano, Koichi Kume, and Kotaro Tsuru, 2016, "Mugentei Seishain To Gentei Seishain No Chingin Kakusa (Wage Gap Between Non-limited and Limited Workers)," RIETI Discussion Paper Series, 16-J-061.

Yoo, W., and I. Oh, 2017, "Effect of Work-Family Balance Policy on Job Selection and Social Sustainability: The Case of South Korea," Sustainability 9(5), p. 849. 


\section{APPendiX 1. Key Parts of THe SuRVey Questionnaire}

We would be grateful if you could spare the time to take part in our survey - it should only take around 15-20 minutes to complete. The survey concerns the working life of employees in Japan. The research is being conducted by researchers from the National Graduate Institute for Policy Studies

We would like to ask following questions to people who are 20-59 years old and have had at least one job (excluding part-time work while in school or college, self-employed, and family employee.).

Please click on the appropriate answer to each question or type in your answer where required.

\section{(General questions about work, experience and education, omitted)}

We are now going to show you a series of hypothetical job choices. Each job description will have some information about the working conditions. In each question you must select the job you like the most and the job you like the least. There are total 8 questions.

In the options we will give you information about the total annual wage (including overtime pay and bonuses), the amount of overtime, the possibility of relocation, the possibility of changes in job contents and employment stability. The jobs included are all regular jobs, meaning they are not temporary jobs with low employment stability. Please study the information carefully, then make your choice.

What about other features of the job, such as the type of work, the size of the company and so on? Here, we want you to suppose that the other features of the job are almost the same as your current job or the last full-time job you held. 
Q21: Please choose the job you like the MOST and the job you like the LEAST from Job A, Job B, and Job C below.

\begin{tabular}{|c|c|c|c|}
\hline Example & Job A & Job B & Job C \\
\hline Total annual wage & 4 million yen & 3 million yen & 3.5 million yen \\
\hline \multirow[t]{2}{*}{ Overtime } & More than 45 & zero & zero \\
\hline & Hours/month & & \\
\hline Employment & Medium & High & Medium \\
\hline \multicolumn{4}{|l|}{ Stability } \\
\hline $\begin{array}{l}\text { Possibility of } \\
\text { relocation }\end{array}$ & Zero & Zero & Some \\
\hline $\begin{array}{l}\text { Possibility of } \\
\text { intra-firm transfer }\end{array}$ & Some & Zero & Zero \\
\hline Which Job do you & O & $\mathrm{O}$ & O \\
\hline \multicolumn{4}{|l|}{ LIKE the MOST? } \\
\hline Which Job do you & 0 & O & 0 \\
\hline
\end{tabular}

(Choice question like above example * eight times (Q21-Q28), omitted,

There are 4 blocks of eight choice sets, so there are in total 32 choice sets)

The following questions ask you about your assessment of the above questions

Q29: Did you ignore any of the below attributes when you make the hypothetical job choice in Q21-Q28? [check all that apply]

Total annual wage

Overtime

Employment Stability

Possibility of relocation

Possibility of intra-firm transfer

None of above

Q.30: How true for you is each of the following statements? [choose from True, Basically true, I cannot say either way, Not really true, Untrue]

- The choice sets presented were realistic

- The hypothetical situation applied to me

Q.31. Now, suppose you were offered a job with the following features:

- Overtime: More than 45 hours per month

- Employment stability: High

- Possibility of intra-firm transfer: Some

- Possibility of relocation: Some 


\section{Would you switch to this job if [please choose all that apply]: \\ The wage was $1 \mathrm{~m}$ Yen per year lower than your current salary \\ The wage was the same as your current salary \\ The wage was $1 \mathrm{~m}$ Yen per year higher than your current salary

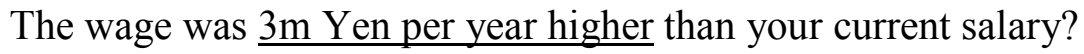 \\ None of above}

(Questions about family and home-life, omitted)

Q48: How much guilty would you feel by acting as each of the statement below. If the situation does not apply to you or your spouse/partner, please answer as you imagine what you would feel in the situation. [choose from Very Guilty, Somewhat Guilty, I cannot say either way, Not really guilty, Not Guilty at all]

- I took paid leave when my managers and colleagues are working a lot of overtime.

- I left the office on time for a family event when my managers and colleagues are working.

- I did not prepare healthy dinner for me and for my family for the entire week.

- Because I was working I missed my child(ren)'s event which I had promised to go.

- I did not see my elderly parents or other relatives who needs care for the last one month.

- Not earning enough income to satisfy the demands of my child (extra-academic activities, clothes, games...)

- Not being able to spend time with my child when we are at home because I must perform tasks that do not concern the family.

\section{Thank you for your help with this study!}


APPENDIX 2: EXTENDED MODEL (MODEL 2)

Model 2

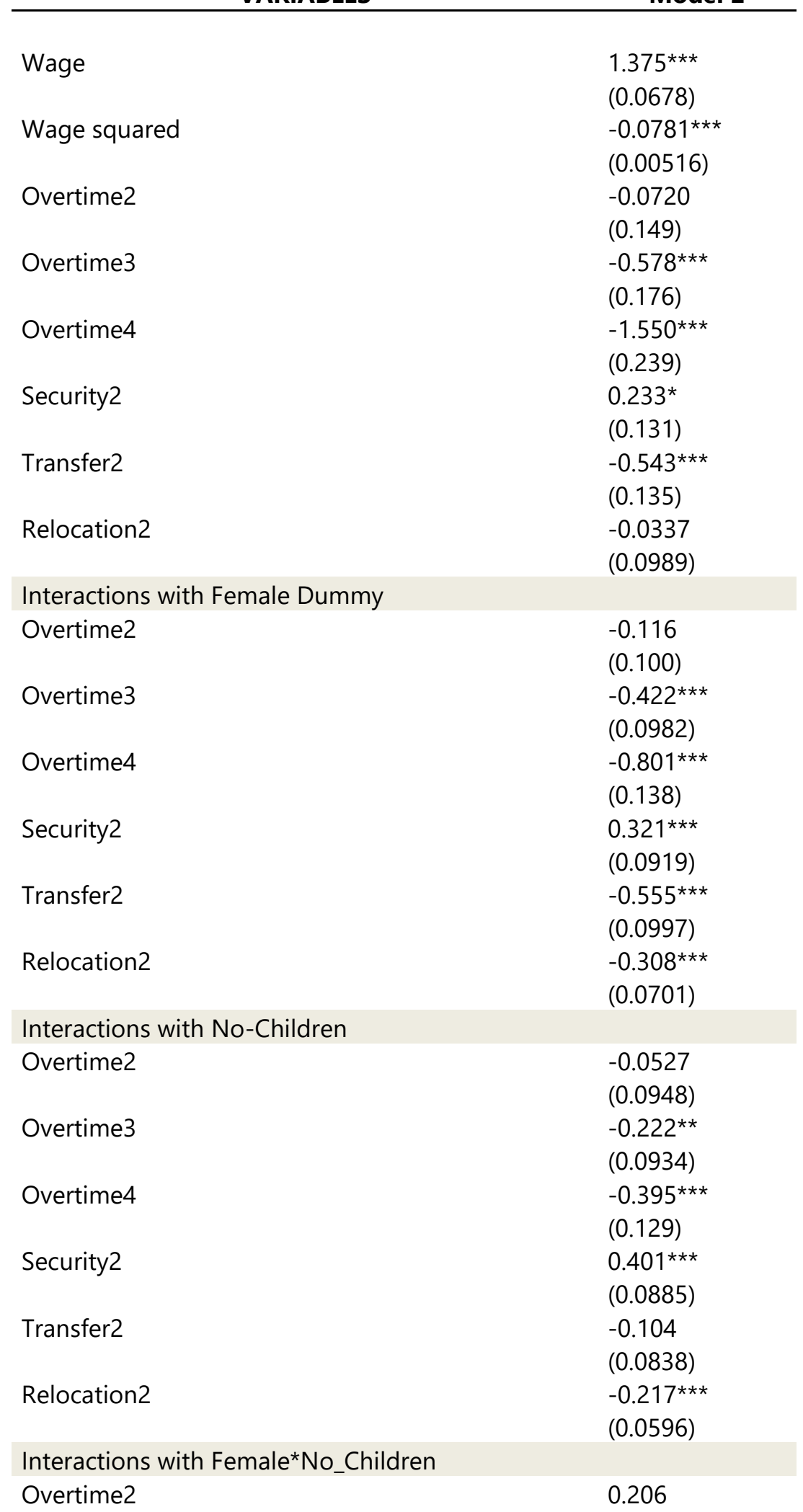

CInternational Monetary Fund. Not for Redistribution 


\begin{tabular}{|c|c|}
\hline & $(0.132)$ \\
\hline \multirow[t]{2}{*}{ Overtime3 } & 0.224 \\
\hline & $(0.138)$ \\
\hline \multirow[t]{2}{*}{ Overtime4 } & $0.465^{* *}$ \\
\hline & $(0.190)$ \\
\hline \multirow[t]{2}{*}{ Security2 } & $-0.312^{* * *}$ \\
\hline & $(0.117)$ \\
\hline \multirow[t]{2}{*}{ Transfer2 } & 0.130 \\
\hline & $(0.132)$ \\
\hline \multirow[t]{2}{*}{ Relocation2 } & $0.265^{* * *}$ \\
\hline & $(0.0916)$ \\
\hline \multicolumn{2}{|c|}{ Interactions with age cohorts } \\
\hline \multirow[t]{2}{*}{ 30s \# Overtime2 } & -0.0118 \\
\hline & $(0.127)$ \\
\hline \multirow[t]{2}{*}{ 40s \# Overtime2 } & 0.0700 \\
\hline & $(0.137)$ \\
\hline \multirow[t]{2}{*}{ 50s \# Overtime2 } & 0.0346 \\
\hline & $(0.133)$ \\
\hline \multirow[t]{2}{*}{ 30s \# Overtime3 } & $0.270^{*}$ \\
\hline & $(0.161)$ \\
\hline \multirow[t]{2}{*}{ 40s \# Overtime3 } & $0.390 * *$ \\
\hline & $(0.169)$ \\
\hline \multirow[t]{2}{*}{ 50s \# Overtime3 } & $0.284^{*}$ \\
\hline & $(0.166)$ \\
\hline \multirow[t]{2}{*}{ 30s \# Overtime4 } & $0.613^{* * *}$ \\
\hline & $(0.221)$ \\
\hline \multirow[t]{2}{*}{ 40s \# Overtime4 } & $0.704^{* * *}$ \\
\hline & $(0.231)$ \\
\hline \multirow[t]{2}{*}{ 50s \# Overtime4 } & $0.606^{* * *}$ \\
\hline & $(0.229)$ \\
\hline \multirow[t]{2}{*}{ 30s \# Security2 } & -0.0415 \\
\hline & $(0.108)$ \\
\hline \multirow[t]{2}{*}{ 40s \# Security2 } & -0.0279 \\
\hline & $(0.115)$ \\
\hline \multirow[t]{2}{*}{ 50s \# Security2 } & -0.147 \\
\hline & $(0.116)$ \\
\hline \multirow[t]{2}{*}{ 30s \# Transfer2 } & $-0.253^{* *}$ \\
\hline & $(0.117)$ \\
\hline \multirow[t]{2}{*}{ 40s \# Transfer2 } & -0.183 \\
\hline & $(0.124)$ \\
\hline \multirow[t]{2}{*}{ 50s \# Transfer2 } & $-0.237^{*}$ \\
\hline & $(0.125)$ \\
\hline 30s \# Relocation2 & -0.0534 \\
\hline
\end{tabular}

CInternational Monetary Fund. Not for Redistribution 
40s \# Relocation2

(0.0845)

40s \# Relocation2

$-0.146$

50s \# Relocation2

(0.0907)

50s \# Relocation2

$-0.131$

Interaction with Educated Dummy

Overtime2

(0.0900)

Overtime3

0.0394

(0.0667)

0.0895

(0.0706)

Overtime4

$0.185^{*}$

(0.0950)

Security2

$-0.255^{\star * *}$

(0.0581)

Transfer2

$0.208^{* * *}$

(0.0671)

Relocation2

0.0336

(0.0458)

Observations

25,104

Number of groups

8,368

Robust standard errors in parentheses; ${ }^{* \star} p<0.01,{ }^{* *} p<0.05,{ }^{*} p<0.1$

Note: Educated $=1$ if graduated from 4 -year universities or graduate schools and

Educated $=0$ otherwise.

CInternational Monetary Fund. Not for Redistribution 